Sharif University of Technology
Scientia Iranica
SCIENTIA
I RAN I C A
http://scientiairanica.sharif.edu

\title{
Determination of limit-states for near-fault seismic fragility assessment of concrete gravity dams
}

\author{
M.A. Sotoudeh ${ }^{\mathrm{a}}$, M. Ghaemian ${ }^{\mathrm{b}, *}$, and A. Sarvghad Moghadam ${ }^{\mathrm{c}}$ \\ a. Department of Civil Engineering, Science and Research Branch, Islamic Azad University (IAU), Tehran, Iran. \\ b. Department of Civil Engineering, Sharif University of Technology, Tehran, Iran. \\ c. Structural Engineering Research Center, International Institute of Earthquake Engineering and Seismology, Tehran, Iran.
}

Received 9 January 2017; received in revised form 2 August 2017; accepted 29 August 2017

\section{KEYWORDS}

Concrete dam;

Limit state;

Performance;

Fragility;

Incremental dynamic analysis.

\begin{abstract}
Fragility curve, based on the Performance-Based Earthquake Engineering (PBEE), is a fundamental tool for assessing the probabilistic seismic performance of concrete gravity dams. Determination of the dam Limit-States (LSs) is necessary for estimation of fragility curve. In this research, four LSs in seismic performance of massive structure have been utilized for Pine Flat dam. To address this, the Incremental Dynamic Analysis (IDA) method has been applied to the integrated dam-reservoir finite-element model. Evaluation of seismic behavior, demand and capacity of the tallest monolith has been done by implementing IDA. A new comprehensive method in terms of IDA and statistical analysis has been used for determination of each defined LS based on the certain value of the Engineering Demand Parameter (EDP). To assess probabilistic performance of the dam, the exceeding probability of the LSs curves has been developed at various intensity measures based on the tree EDPs. It was found that the defined LSs had the capability indeed to be used in probabilistic framework.
\end{abstract}

(C) 2019 Sharif University of Technology. All rights reserved.

\section{Introduction}

Since the beginning of the construction of large dams in the 19th century [1] till now, complete seismic failure of concrete dams has not been reported. However, recent devastating earthquakes have indicated that concrete dams are vulnerable to ground motion shaking [2-5] and their seismic failure is probable. Collapse of a concrete dam and the sudden release of impounded water can lead to human casualties and financial losses. Hence, there are serious concerns regarding the seismic

\footnotetext{
*. Corresponding author. Tel.: +982166164242;

Fax: +982166014828

E-mail addresses: ma.sotoudeh@gmail.com (M.A.

Sotoudeh); ghaemian@sharif.edu (M. Ghaemian);

moghdam@iiees.ac.ir (A. Sarvghad Moghadam).
}

performance and reliability of concrete dams, especially aging ones, for owners, designers, and contractors. Therefore, the performance of concrete dams is of paramount importance in the seismic safety assessment of infrastructure networks, nowadays, in probabilistic framework.

Performance-Based Earthquake Engineering (PBEE), the developed generation in Pacific Earthquake Engineering Research (PEER) center, is one of the full-fledged probabilistic seismic risk assessment methods [6]. PEER PBEE method consists of four distinct stages, i.e., hazard analysis, structural analysis, damage analysis, and loss analysis [7], that have been developed in building and bridge industries. In the context of probabilistic assessment of concrete dams, the Potential Failure Mode (PFM) analysis is the accepted approach [8] which may seem insufficient [9]. In order to broaden this procedure, 
PFM has been merged with PBEE by Hariri-Ardebili in which the concept of fragility has been used in established hybrid method [10].

Fragility curve constitutes one of the key components of probabilistic seismic performance assessment of the structural systems whose determination is the main goal of the third stage of PBEE, i.e. damage analysis. Fragility curve is a performance proxy that relates the intensity measure to the probability of exceeding a Limit State (LS) by considering the aleatory (ground motion record variability) and/or epistemic (material and modeling) uncertainties.

Different approaches can be utilized to derive the fragility curves, including empirical, judgmental, analytical, and hybrid methods. In the case of concrete dams, most researchers have derived the fragility curves through analytical approaches [9]. The frequent use of numerical approaches in fragility curve methodologies would be justifiable by paying attention to either insufficient damage records or unique size and shape of each dam. Some structural analysis methods, such as Multiple Stripe Analysis (MSA) [11], Incremental Dynamic Analysis (IDA) [12,13], cloud analysis (CLA) [14], and Endurance Time Analysis (ETA) [15], are suitable for fragility analysis as they have multiple seismic-based excitations. Among the mentioned methods, IDA [16] is most robust and useful method that is compatible with the second stage of PBEE methodology. IDA curve illustrates the variations of structure's behavior when shifted from linear into nonlinear and, eventually, into collapse state. Thus, important achievements of IDA are performance LSs, demand, and capacity of structure.

Since 1998 [17], many studies have been performed on probabilistic safety assessment of concrete dams using fragility concept. These studies have focused on developing fragility analysis into dam engineering field along with consideration of aleatory and/or epistemic uncertainties through different structural analysis methods. However, these studies have used non-validated thresholds of LSs to derive the fragility curves for concrete dams, reducing the reliability of the results. In other words, enough attention has not been paid to the intermediate performance levels and their thresholds in relevant studies. Therefore, one of the major innovations of this study is to fill this gap with previous articles by IDA and statistical methods. The literature review of these studies is illustrated in Table 1. In addition, the used EDPs in the fragility analysis are presented in Table 1 for each research case.

The main objective of this research is to define the authoritative LSs and determine the thresholds for the seismic assessment of concrete dam in a probabilistic framework. To address this purpose, the full seismic behavior of Pine Flat dam is captured through IDA method under near-fault excitations. Further, single-
IDA curves are generated for selective EDPs. Then, a comparison between single-IDA curves and damage statues of dam body will be made and investigated by the simultaneous study of IDA curve, crack profiles, and Damage-Displacement Time History (DDTH) curves. This study, for the first time, calculated the DDTH curve with a new perspective on the concrete dam seismic response and cracking and used scaling approach to the records. Using a new comprehensive method in terms of IDA and statistical analysis for determining seismic LSs of concrete gravity dams and their thresholds is the main contribution of this paper. In this research, four incremental LSs are defined as Base Level crack initiation (BLci), yielding, upper part crack initiation (NZci), and Collapse Prevention (CP). It is emphasized that considering the equivalent value of each EDP (as crest displacement, DFE, crack ratio, etc.) for each significant performance level (as BLci, yielding, NZci, CP, etc.) is one of the most important aims of this research. Finally, seismic safety of the dam is assessed by near-fault fragility curves using the defined LSs.

\section{Incremental dynamic analysis}

In compatibility with the second stage of PEER PBEE analysis methodology, IDA technique was utilized to estimate the structural responses to various hazard levels. IDA study has a dynamical and probabilistic basis and provides useful and comprehensive results while considering the aleatory uncertainties [16]. This method can demonstrate the variety of structural seismic behaviors and provide answers to major questions, such as when and how the system behaves both in linear and nonlinear regions, when it reaches yield and ultimate states, what the structural performance of LSs and their capacities is, etc. The flowchart of IDA methodology is shown in Figure 1.

\section{Numerical modeling description}

The Pine Flat concrete gravity dam was built on the Kings River in the United States [32]. It consists of 37 monoliths, of $15.2 \mathrm{~m}$ width, which forms $560 \mathrm{~m}$ crest length. The finite-element model of the tallest nonoverflow monolith of Pine Flat dam and its reservoir, with $122 \mathrm{~m}$ height, is shown in Figure 2. This particular dam is selected as a case study for the purpose of nonlinear fracture analysis using IDA technical approach.

In this research, the tallest monolith of the dam was modelled using $2 \mathrm{D}$ plane stress into the analysis. Although dam-foundation interaction is an important aspect in the dynamic analysis of dams, it is neglected to avoid high computational time and cost. Therefore, the foundation is assumed rigid with no sliding plane at the dam-foundation interface. Only material nonlin- 
Table 1. Summary of the probabilistic safety assessment of concrete dams using fragility concept [9].

\begin{tabular}{|c|c|c|c|c|c|c|c|c|c|c|c|c|c|c|c|c|c|c|c|c|c|c|c|c|c|c|}
\hline$\dot{0}$ &  & 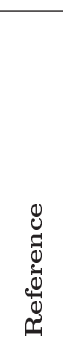 &  & 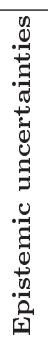 & 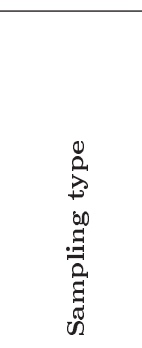 & 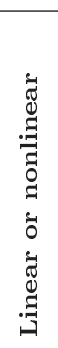 & 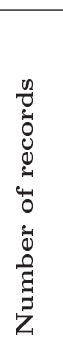 & 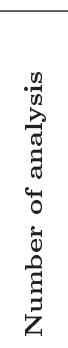 & 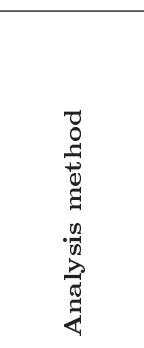 &  & 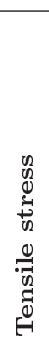 & 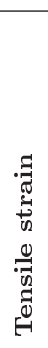 &  & 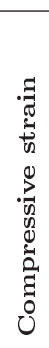 & 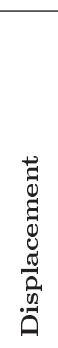 & 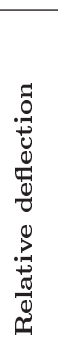 & 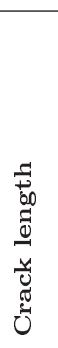 & 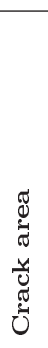 & 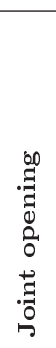 & 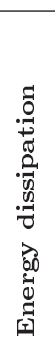 & 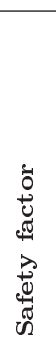 &  & $\begin{array}{l}\mathscr{n} \\
\text { Ũ } \\
\end{array}$ & 具 & $\begin{array}{l}\tilde{n} \\
\stackrel{n}{n} \\
\stackrel{n}{n}\end{array}$ & $\begin{array}{l}0 \\
0 \\
2 \\
+ \\
\vdots \\
\vdots \\
0 \\
0 \\
0 \\
0\end{array}$ \\
\hline 1 & $\begin{array}{l}\text { de Araújo } \\
\& \text { Awruch }\end{array}$ & {$[17]$} & GD & $\sqrt{ }$ & MCS & NL & 50 & 50 & ynamic & $\sqrt{ }$ & $\sqrt{ }$ & $\times$ & $\sqrt{ }$ & $x$ & $\times$ & $x$ & $\times$ & $\times$ & $\times$ & $\times$ & $\sqrt{ }$ & $x$ & $\times$ & $x$ & $x$ & $\mathrm{C}$ \\
\hline 2 & $\begin{array}{c}\text { Tekie } \\
\& \text { Ellingwood }\end{array}$ & {$[18]$} & GD & $\sqrt{ }$ & LHS & NL & 12 & 72 & IDA & $\sqrt{ }$ & $\sqrt{ }$ & $\times$ & $\times$ & $\sqrt{ }$ & $\times$ & $\sqrt{ }$ & $\times$ & $\times$ & $x$ & $x$ & $x$ & $x$ & $\times$ & $\times$ & $x$ & $\mathrm{C}$ \\
\hline 3 & $\begin{array}{c}\text { Mirzahosseini Kashani } \\
\text { \& Ghaemian }\end{array}$ & [19] & GD & $x$ & $x$ & NL & 6 & 42 & IDA & $\times$ & $\times$ & $\times$ & $x$ & $\times$ & $\times$ & $x$ & $\sqrt{ }$ & $\sqrt{ }$ & $\times$ & $\times$ & $x$ & $\times$ & $\times$ & $\times$ & $\times$ & $\mathrm{C}$ \\
\hline 4 & $\begin{array}{l}\text { Lupoi } \\
\& \text { Callari }\end{array}$ & {$[20]$} & GD & $\sqrt{ }$ & MCS & LE & 10 & 60 & Dynamic & $\sqrt{ }$ & $\sqrt{ }$ & $\times$ & $x$ & $\times$ & $\times$ & $x$ & $\sqrt{ }$ & $\times$ & $x$ & $x$ & $x$ & $\times$ & $x$ & $x$ & $x$ & $\mathrm{C}$ \\
\hline 5 & Yücel & {$[21]$} & GD & $\sqrt{ }$ & Parametric & $\mathrm{LE}$ & 202 & 2700 & $\begin{array}{c}\text { Single } \\
\text { dynamic }\end{array}$ & $\times$ & $\sqrt{ }$ & $\times$ & $\times$ & $\times$ & $\times$ & $x$ & $\times$ & $\times$ & $\times$ & $\times$ & $x$ & $\times$ & $\sqrt{ }$ & $\sqrt{ }$ & $\times$ & $\mathrm{C}$ \\
\hline 6 & $\begin{array}{l}\text { Abdelhamid } \\
\text { et al. }\end{array}$ & {$[22]$} & GD & $\sqrt{ }$ & LHS & NL & 6 & 60 & Dynamic & $\sqrt{ }$ & $\sqrt{ }$ & $\times$ & $\sqrt{ }$ & $\times$ & $\sqrt{ }$ & $\times$ & $\times$ & $\times$ & $\times$ & $\times$ & $\times$ & $\times$ & $\times$ & $\times$ & $\times$ & $\mathrm{C}$ \\
\hline 7 & Ju \& Jung & {$[23]$} & OW & $x$ & $x$ & $\mathrm{LE}$ & 60 & 420 & IDA & $x$ & $\sqrt{ }$ & $\times$ & $\sqrt{ }$ & $\times$ & $\sqrt{ }$ & $\times$ & $\times$ & $\times$ & $x$ & $x$ & $\times$ & $\times$ & $\times$ & $\times$ & $x$ & $\mathrm{C}$ \\
\hline 8 & Ghanaat et al. & {$[24]$} & GD & $\sqrt{ }$ & LHS & NL & 10 & 100 & IDA & $\sqrt{ }$ & $\times$ & $\times$ & $\times$ & $\times$ & $\times$ & $\times$ & $\times$ & $\times$ & $\times$ & $\times$ & $\times$ & $\times$ & $\times$ & $\times$ & $x$ & $\mathrm{C}$ \\
\hline 9 & $\begin{array}{l}\text { Hariri-Ardebili } \\
\quad \& \text { Saouma }\end{array}$ & {$[14]$} & GD & $x$ & $\times$ & NL & 100 & 100 & CLA & $\sqrt{ }$ & $\times$ & $\times$ & $x$ & $\times$ & $\sqrt{ }$ & $x$ & $\times$ & $\times$ & $\sqrt{ }$ & $x$ & $\times$ & $\sqrt{ }$ & $\times$ & $x$ & $\times$ & $\mathrm{C} / \mathrm{S}$ \\
\hline 10 & $\begin{array}{l}\text { Hariri-Ardebili } \\
\text { \& Saouma }\end{array}$ & {$[25]$} & GD & $x$ & $\times$ & NL & 211 & 1200 & IDA & $\sqrt{ }$ & $\times$ & $\times$ & $x$ & $\times$ & $\sqrt{ }$ & $x$ & $x$ & $\times$ & $\sqrt{ }$ & $\times$ & $\times$ & $\sqrt{ }$ & $x$ & $x$ & $\times$ & $\mathrm{C} / \mathrm{S}$ \\
\hline 11 & $\begin{array}{l}\text { Hariri-Ardebili } \\
\text { \& Saouma }\end{array}$ & {$[15]$} & GD & $\sqrt{ }$ & LHS & NL & 1 & 200 & ETA & $\sqrt{ }$ & $\times$ & $x$ & $x$ & $\times$ & $\sqrt{ }$ & $x$ & $\times$ & $\times$ & $\sqrt{ }$ & $x$ & $x$ & $\sqrt{ }$ & $\times$ & $x$ & $x$ & $\mathrm{C}$ \\
\hline 12 & Bernier et al. & {$[26]$} & GD & $\sqrt{ }$ & LHS & NL & 20 & 160 & IDA & $\sqrt{ }$ & $\times$ & $\times$ & $\times$ & $\times$ & $x$ & $\times$ & $\times$ & $\times$ & $x$ & $\times$ & $\times$ & $\times$ & $x$ & $x$ & $\times$ & $\mathrm{C}$ \\
\hline 13 & Bernier et al. & {$[27]$} & GD & $\sqrt{ }$ & LHS & NL & 20 & 140 & MSA-IDA & $\sqrt{ }$ & $\times$ & $\times$ & $\times$ & $\times$ & $\times$ & $x$ & $\times$ & $x$ & $\times$ & $\times$ & $x$ & $x$ & $x$ & $\times$ & $\times$ & $\mathrm{C}$ \\
\hline 14 & $\begin{array}{c}\text { Ansari } \\
\text { \& Agarwal }\end{array}$ & {$[28]$} & GD & $\times$ & $\times$ & NL & 17 & 170 & IDA & $\times$ & $\times$ & $\times$ & $\times$ & $\times$ & $\sqrt{ }$ & $x$ & $\times$ & $\times$ & $x$ & $\sqrt{ }$ & $\sqrt{ }$ & $\sqrt{ }$ & $\times$ & $x$ & $\times$ & $\mathrm{C}$ \\
\hline 15 & Yao et al. & {$[29]$} & $\mathrm{AD}$ & $\times$ & $x$ & $\mathrm{NL}$ & 18 & 18 & MSA-IDA & $\sqrt{ }$ & $\times$ & $x$ & $x$ & $\times$ & $x$ & $x$ & $\times$ & $\times$ & $\sqrt{ }$ & $x$ & $x$ & $\times$ & $x$ & $x$ & $\times$ & $x$ \\
\hline 16 & Zhong et al. & {$[30]$} & $\mathrm{AD}$ & $\sqrt{ }$ & MCS & NL & Unkn & nown & Dynamic & $\times$ & $x$ & $\times$ & $x$ & $\times$ & $x$ & $\times$ & $x$ & $\sqrt{ }$ & $x$ & $x$ & $x$ & $x$ & $x$ & $x$ & $\times$ & $\mathrm{C}$ \\
\hline 17 & $\begin{array}{l}\text { Kadkhodayan } \\
\text { et al. }\end{array}$ & {$[31]$} & $\mathrm{AD}$ & $x$ & $\times$ & NL & 9 & 80 & IDA & $\times$ & $\sqrt{ }$ & $\times$ & $\times$ & $\times$ & $\times$ & $x$ & $\times$ & $\times$ & $x$ & $\times$ & $\times$ & $\times$ & $\times$ & $\times$ & $\times$ & $\mathrm{C}$ \\
\hline 18 & Hariri-Ardebili et al. & {$[11]$} & $\mathrm{AD}$ & $x$ & $\times$ & NL & 9 & 54 & MSA & $\sqrt{ }$ & $\sqrt{ }$ & $\sqrt{ }$ & $x$ & $\times$ & $\sqrt{ }$ & $x$ & $\times$ & $\sqrt{ }$ & $\sqrt{ }$ & $x$ & $\times$ & $\times$ & $\sqrt{ }$ & $\sqrt{ }$ & $\sqrt{ }$ & $\mathrm{C}$ \\
\hline
\end{tabular}

Note: AD: Arch Dam; C: Curve; CLA: Cloud Analysis; ETA: Endurance Time Analysis; GD: Gravity Dam;

IDA: Incremental Dynamic Analysis; LE: Linear; LHS: Latin Hypercube Sampling; MCS: Monte Carlo Simulation;

MSA: Multiple Stripe Analysis; NL: Non-linear; OW: Overflow Weir; S: Surface.

earity was incorporated. Thus, overstressing is a major failure mode as tensile cracking at the base within the homogenous dam body, where the compressive crushing was neglected. The concrete material was simulated using smeared crack model [33]. Table 2 shows the mass concrete properties used in this study.

The Finite-Element (FE) model was created for coupled dam- reservoir system. This model consists of 1984 quadratic solid elements for the concrete dam, in which each node of solid elements has two Degrees Of Freedom (DOF) in $x$ and $y$ directions. Reservoir was modeled using 2065 four-node fluid elements. The fluid elements have three DOFs in each node, and two of them are translation DOFs, which are active only at solid-fluid interface nodes, but the other is pressure DOF. Further, the number of contraction elements on the solid-reservoir face of the fluid is 59 here. Figure 2 shows the FE mesh of 2D plane stress model of flexible dam-reservoir system.

In this study, staggered displacement method was used for dam-reservoir interaction in a nonlinear time history analysis. The Rayleigh elasto-brittle damping

Table 2. Mechanical properties of mass concrete.

\begin{tabular}{lccc}
\hline Characteristics & Symbol & Value & Unit \\
\hline Modulus of elasticity & $E_{c}$ & 27.58 & $\mathrm{GPa}$ \\
Mass density & $\rho_{c}$ & 2400.00 & $\mathrm{~kg} / \mathrm{m}^{3}$ \\
Poisson's ratio & $\nu_{c}$ & 0.20 & - \\
Tensile strength & $\sigma_{t}$ & 2.70 & $\mathrm{MPa}$ \\
Compressive strength & $\sigma_{c}$ & 27.00 & $\mathrm{MPa}$ \\
Fracture energy & $G_{f}$ & 300.00 & $\mathrm{~N} / \mathrm{m}$ \\
Dynamic magnification factor & - & 1.20 & - \\
\hline
\end{tabular}




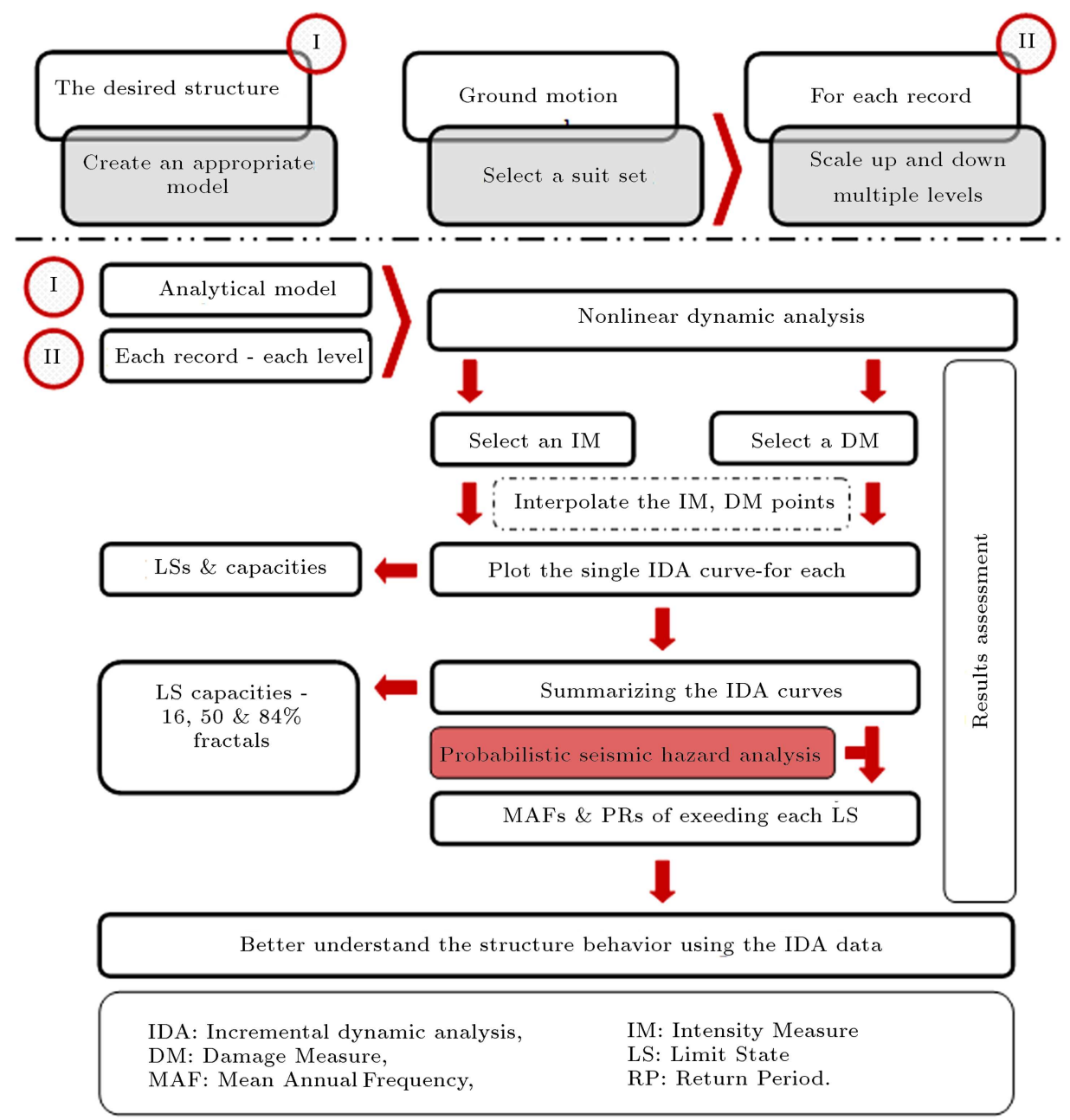

Figure 1. Flowchart of IDA technique.
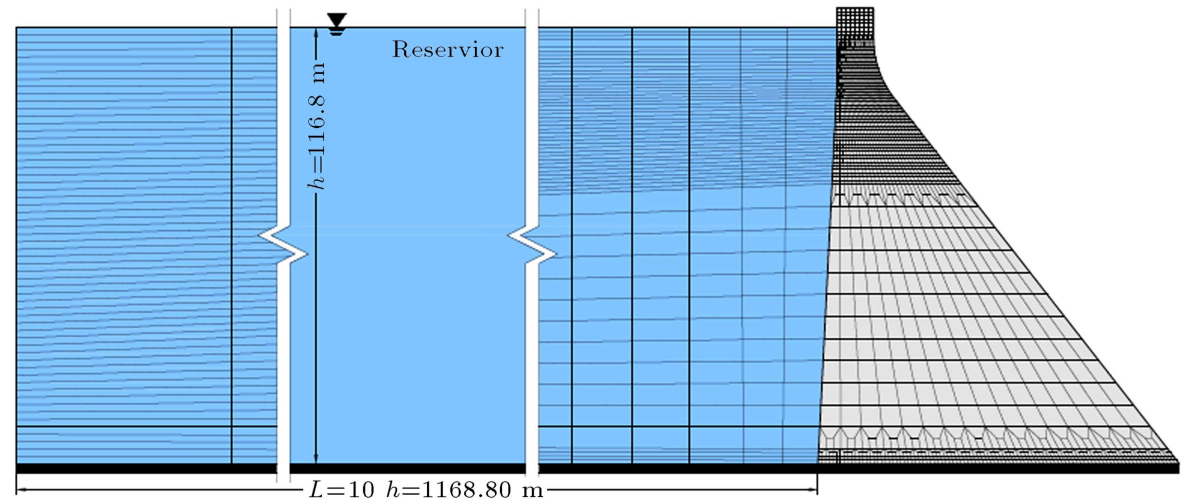

Figure 2. FE mesh of the tallest non-overflow monolith of pine flat concrete gravity dam and its reservoir.

model was adopted using stiffness-proportional damping coefficients of 0.0044 . Therefore, it produced $5 \%$ critical damping ratio in the first vibration mode of the coupled dam-reservoir system based on a rigid foundation. In order to prevent numerical instability, the effects of the damping force are eliminated by ignoring mass proportional damping coefficient.

\section{Selection of earthquake record}

Earth excitation characteristics, such as amplitude, frequency content, energy, and strong motion duration, highly affect the results of nonlinear dynamic analysis. In addition, the direction of pulses within the motion should be added to these characteristics. Near-fault 
Table 3. List of the selected near-fault pulse-like ground motions for IDA of pine flat concrete gravity dam.

\begin{tabular}{|c|c|c|c|c|c|c|c|c|c|}
\hline No. & Identifier & Earthquake & Date & Station & Component & $M_{s}$ & $\begin{array}{c}\text { Closest } \\
\text { distance }\end{array}$ & $\begin{array}{l}\text { Site } \\
\text { class }\end{array}$ & Source \\
\hline 1 & gnp01n & Chi-Chi, Taiwan & $1999 / 09 / 20$ & TCU046 & $\mathrm{N}$ & 7.6 & 14.34 & $1 / \mathrm{A}$ & CWB/USGS \\
\hline 2 & gnp01e & Chi-Chi, Taiwan & $1999 / 09 / 20$ & TCU046 & W & 7.6 & 14.34 & $1 / \mathrm{A}$ & CWB/USGS \\
\hline 3 & $g n p 02 n$ & Chi-Chi, Taiwan & $1999 / 09 / 20$ & CHY006 & $\mathrm{N}$ & 7.6 & 14.93 & $1 / \mathrm{C}$ & CWB/USGS \\
\hline 4 & gnp02e & Chi-Chi, Taiwan & $1999 / 09 / 20$ & CHY006 & $\mathrm{E}$ & 7.6 & 14.93 & $1 / \mathrm{C}$ & CWB/USGS \\
\hline 5 & gnp03n & Chi-Chi, Taiwan & $1999 / 09 / 20$ & CHY035 & $\mathrm{N}$ & 7.6 & 18.12 & $1 / \mathrm{C}$ & CWB/USGS \\
\hline 6 & gnp03e & Chi-Chi, Taiwan & $1999 / 09 / 20$ & CHY035 & $\mathrm{W}$ & 7.6 & 18.12 & $1 / \mathrm{C}$ & CWB/USGS \\
\hline 7 & gnp04n & Coalinga & $1983 / 07 / 22$ & 1651 Transmitter hill & 270 & 5.7 & 9.2 & $\mathrm{~A}$ & Gx. \\
\hline 8 & gnp04e & Coalinga & $1983 / 07 / 22$ & 1651 Transmitter hill & 360 & 5.7 & 9.2 & A & $\mathrm{Gx}$. \\
\hline 9 & gnp05n & Coyote Lake & $1979 / 08 / 06$ & 57383 Gilroy array \#6 & 230 & 5.6 & 3.1 & $\mathrm{~B} / \mathrm{B}$ & Gx./USGS \\
\hline 10 & gnp05e & Coyote Lake & $1979 / 08 / 06$ & 57383 Gilroy array \#6 & 320 & 5.6 & 3.1 & $\mathrm{~B} / \mathrm{B}$ & Gx./USGS \\
\hline 11 & gnp06n & Kocaeli, Turkey & $1999 / 08 / 17$ & Gebze & 000 & 7.8 & 17.0 & $\mathrm{~A} / \mathrm{A}$ & Gx./USGS \\
\hline 12 & gnp06e & Kocaeli, Turkey & $1999 / 08 / 17$ & Gebze & 270 & 7.8 & 17.0 & $\mathrm{~A} / \mathrm{A}$ & Gx./USGS \\
\hline 13 & $\operatorname{gnp} 07 \mathrm{n}$ & Landers & $1992 / 06 / 28$ & 24 Lucerne & 000 & 7.4 & 1.1 & $\mathrm{~A} / \mathrm{A}$ & Gx./USGS \\
\hline 14 & gnp07e & Landers & $1992 / 06 / 28$ & 24 Lucerne & 270 & 7.4 & 1.1 & $\mathrm{~A} / \mathrm{A}$ & Gx./USGS \\
\hline 15 & gnp08n & Mammoth Lakes & $1980 / 05 / 25$ & $\begin{array}{l}54214 \text { Long } \\
\text { Valley dam } \\
\text { (U/L abut) }\end{array}$ & 000 & 6.1 & 15.5 & A & $\mathrm{Gx}$. \\
\hline 16 & gnp08e & Mammoth Lakes & $1980 / 05 / 25$ & $\begin{array}{l}54214 \text { Long } \\
\text { Valley dam (U/L abut) }\end{array}$ & 090 & 6.1 & 15.5 & A & Gx. \\
\hline 17 & gnp09n & Morgan hill & $1984 / 04 / 24$ & $\begin{array}{l}57217 \text { Coyote } \\
\text { Lake dam (SW abut) }\end{array}$ & 285 & 6.1 & 0.1 & A & Gx. \\
\hline 18 & gnp09e & Morgan hill & $1984 / 04 / 24$ & $\begin{array}{l}57217 \text { Coyote } \\
\text { Lake dam (SW abut) }\end{array}$ & 195 & 6.1 & 0.1 & A & Gx. \\
\hline 19 & gnp10n & Morgan hill & $1984 / 04 / 24$ & $\begin{array}{l}57383 \text { Gilroy } \\
\text { Array \#6 }\end{array}$ & 000 & 6.1 & 11.8 & $\mathrm{~B} / \mathrm{B}$ & Gx./USGS \\
\hline 20 & gnp10e & Morgan hill & $1984 / 04 / 24$ & $\begin{array}{l}57383 \text { Gilroy } \\
\text { Array \#6 }\end{array}$ & 090 & 6.1 & 11.8 & $\mathrm{~B} / \mathrm{B}$ & Gx./USGS \\
\hline 21 & gnp11n & Northridge & $1994 / 01 / 17$ & 24207 Pacoima dam (D/S) & 175 & 6.7 & 8.0 & A & Gx. \\
\hline 22 & gnp11e & Northridge & $1994 / 01 / 17$ & 24207 Pacoima dam (D/S) & 265 & 6.7 & 8.0 & A & $\mathrm{Gx}$. \\
\hline 23 & gnp12n & Northridge & $1994 / 01 / 17$ & 24207 Pacoima dam (U/L) & 104 & 6.7 & 8.0 & $\mathrm{~A} / \mathrm{A}$ & Gx./USGS \\
\hline 24 & gnp12e & Northridge & $1994 / 01 / 17$ & 24207 Pacoima dam (U/L) & 194 & 6.7 & 8.0 & $\mathrm{~A} / \mathrm{A}$ & Gx./USGS \\
\hline 25 & gnp13n & San Fernando & $1971 / 02 / 09$ & 279 Pacoima dam & 164 & 6.6 & 2.8 & $\mathrm{~B}$ & USGS \\
\hline 26 & gnp13e & San fernando & $1971 / 02 / 09$ & 279 Pacoima dam & 254 & 6.6 & 2.8 & B & USGS \\
\hline
\end{tabular}

ground motions, containing strong velocity pulses, are of interest in the fields of seismology and earthquake engineering, since their effects on structures are different from non-pulselike records. Thus, a suitable set of twenty-six ground motions is chosen to perform IDA without probabilistic seismic hazard analysis. All records are near-fault ones with the closest distance to the ruptured area ranging from 0.1 to $18.12 \mathrm{~km}$ with directivity effects [34]. All of them have average shear wave velocity greater than $360 \mathrm{~m} / \mathrm{sec}$ or are recorded on the rock or stiff soil as hard site. The surface magnitudes $(\mathrm{Ms})$ of selective motions vary between 6.1 and 7.8, except the two cases which have 5.6 and 5.7 magnitudes and are chosen in the absence of the near-fault pulse-like record on the firm soil. The spectral acceleration of all seismic events is displayed in Figure 3, when all the records are scaled to a PGA of $0.5 \mathrm{~g}$. The selected near-fault pulse-like ground motions are listed in Table 3.

\subsection{Scaling method}

For scaling purposes, each natural accelerogram is scaled to twenty levels of PGA based on two different parameters as PGA and first-mode spectral accelera-

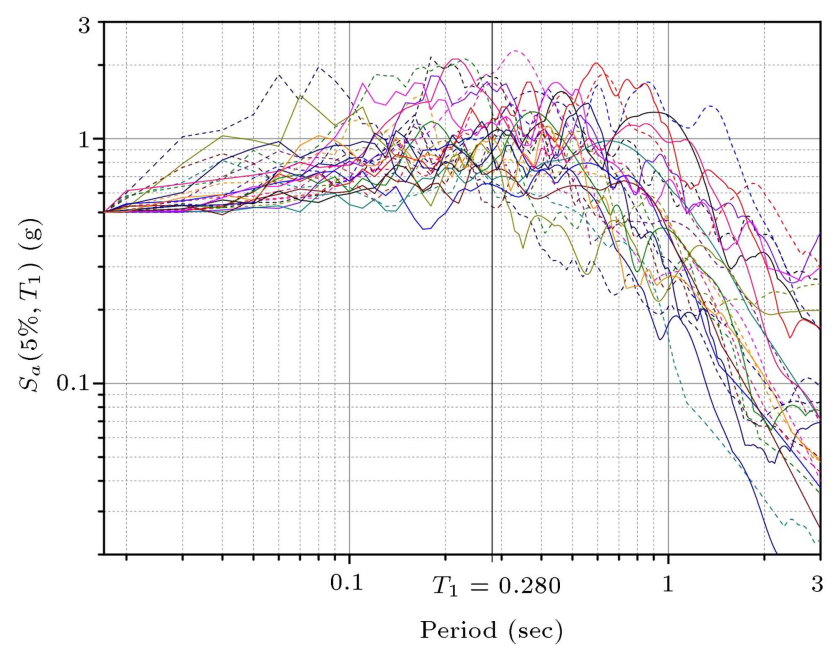

Figure 3. The acceleration response spectra of various earthquakes, while all the records are scaled to PGA = $0.5 \mathrm{~g}$.

tion $\left(S_{a}\left(5 \%, T_{1}\right)\right)$. This approach leads to the consideration of characterizations of both structure and ground motion in determination of seismic input load levels. At the first stage, the amplitude of shaking force from 


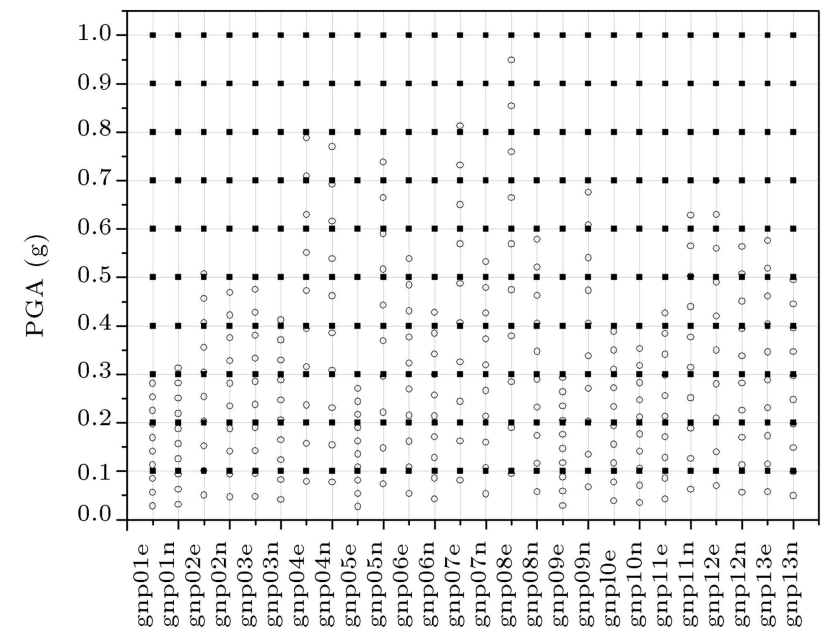

Figure 4. Illustration of all records' scale levels solid rectangle: PGA-based, hollow circles: $S_{a}\left(5 \%, T_{1}\right)$-based).

weak to strong is considered completely. Ten levels of PGA increasing from $0.1 \mathrm{~g}$ to $1.0 \mathrm{~g}$ with $0.1 \mathrm{~g}$ steps have been produced. Moreover, in Figure 4, solid rectangle shows the IM levels based upon the scaled-up PGA. As it is well known, either characteristics of earthquake (such as frequency content and amplitude) or features of structure (such as damping and natural vibration period) have influence on the value of response spectra in the exact vibration period. Therefore, the response spectrum in terms of acceleration has been taken into account in a scaling manner. In this respect, ten extra increasing levels of $5 \%$ damped spectral acceleration at the structure's first-mode period $\left(S_{a}\left(5 \%, T_{1}\right)\right)$ from $0.1 \mathrm{~g}$ to $1.0 \mathrm{~g}$ with equal steps were established. Then, the equivalent PGA of these mentioned levels was considered as other IM levels. IM levels corresponding to the scaled up $\left(S_{a}\left(5 \%, T_{1}\right)\right)$ are shown by the hollow circles in Figure 4.

As can be seen in Figure 4, the distribution of hollow circles is not the same in different records. The ratio of PGA $=1.0 \mathrm{~g}$ to PGA $\mathrm{Pa}_{S}\left(5 T_{1}\right)=1.0 \mathrm{~g}$ shows the differences between these distributions. $\mathrm{PGA}_{S a\left(5 \%, T_{1}\right)=1.0 \mathrm{~g}}$ is the equivalent PGA value of $\left(S_{a}\left(5 \%, T_{1}\right)=1.0\right)$. The minimum value of this ratio is 1.054 and is related to record \#16 (gnp08e: Mammoth Lakes earthquake). Moreover, the maximum value is 3.961 and is related to record \#10 (gnp05e: Coyote Lake earthquake), while $\mathrm{PGA}_{S a}\left(5 \%, T_{1}\right)=1.0 \mathrm{~g}$ is 0.2709 . Relative equality of PGA

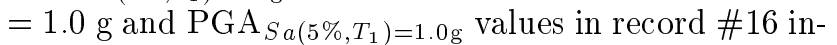
dicates that a significant level of risk, such as a high intense value of PGA $=1.0 \mathrm{~g}$ is created in the scaling of a record based on the scaled up $S_{a}\left(5 \%, T_{1}\right)$, whereas such a situation does not exist in other cases. Therefore, scaling just based on $S_{a}\left(5 \%, T_{1}\right)$ in other records leads to the neglect of some probable hazard levels. Therefore, it is vital to perform scaling procedures based on both parameters. In order to determine twenty levels of
IM, scaling factors are in the range of 0.036 to 8.651 for different ground shakings. Previously, the scale factors between 0.74 and 5.18 were used for IDA studies of concrete gravity dams, where the maximum level of IM was considered as $S_{a}\left(5 \%, T_{1}\right)$ of $1.0 \mathrm{~g}$ [12].

\section{Analysis}

After the numerical modeling and selection of ground motion records, nonlinear time history analyses are done for each scaled level of records. It should be mentioned that the required description of numerical modeling is presented in Section 3; therefore, we continue the subject as follows. In this study, 520 $(26$ records $\times 20$ scaling levels $)$ nonlinear transient dynamic analyses have been carried out using finiteelement NSAG-DRI software [35].

In order to avoid getting off-range results in quantifying the LSs, we have taken benefits of ending analyses criteria. In other words, the ending analyses' criteria ensure us to achieve acceptable results. Here, ending analyses' criteria are defined as either the formation of full crack path at the dam body or the Energy Balance Error (EBE) exceeding 5\%. A full crack path is the one which penetrates into the crosssection of the dam body from the upstream face to downstream, and vice versa. Therefore, the EBE is obtained from the difference between the external energy and the seismic input energy divided by external energy, which can be normalized in percentage and calculated in each time step of analysis by using the mentioned software [36]. The EBE is calculated by Eq. (1) [37]:

$$
E B E(\%)=\left[\frac{(E P+E Q+E H)-(E K+E D+E R)}{(E Q+E H)}\right] \text {, }
$$

where $E P$ is the work of pre-seismic applied force, $E Q$ is the absolute seismic input energy, $E H$ is the work done by hydrodynamic pressure, $E K$ is the absolute kinetic energy, $E D$ is the viscous damping energy, and $E R$ is the nonlinear resorting work.

Thus, based on the defined ending analyses' criteria, none of the analyses has led to complete failure of the dam, and the obtained results correspond to the Collapse Prevention (CP) LS and below it.

In the present research, software verification and numerical modeling validation have been performed using the results of Ghaemian and Ghobarah as benchmark [37]. The results of this modeling are in good agreement with their results in terms of crest displacement, crack profile, and energy responses with the same assumption [37].

\section{Results}

The generation of the single-record IDA curves is 
possible after Intensity Measure (IM) and Damage Measure (DM) selection. IM of earthquake is a scalable positive parameter, which is monotonically increasing with the corresponding scale factor. Routine scalable parameters of ground motion, which can be selected as IM, include Peak Ground Acceleration (PGA), peak ground velocity, spectral acceleration, spectral velocity, Arias Intensity, specific energy density, and maximum incremental velocity $[16,38]$. It should be indicated that the first four items are frequently applied to seismic evaluation of dams through IDA $[12,13,38,39]$. Choosing $S_{a}\left(5 \%, T_{1}\right)$ as IM, by Alembagheri and Ghaemian, has made a lower coefficient of variation in all ranges of DMs in IDA curves [12]. In another research performed by Soysal et al., it was revealed that PGA and spectral velocity at the first mode $\left(S_{v}\left(5 \%, T_{1}\right)\right)$ played a significant role compared to the other IMs in the prediction of cumulative damage states [39]. Since the purpose of this study is the assessment of cumulative damage states, PGA is selected as the main IM parameter.

DM is defined as the additional response of the structure under vibrating loading, and it can be extracted from dynamic analysis output. The parameters of the highest deformation, fracture energy dissipation, and structural stiffness degradation can be utilized in structural seismic evaluation. These DMs can be taken into account as a single scalar in both absolute value and negative/positive parts. In this study, Maximum Crest Displacement (MCD) into D/S and U/S directions, their absolute value (AMCD) and Dissipated Fracture Energy (DFE) are chosen as DMs.

\subsection{Single-IDA curves generation and observation}

Based on the selected DMs and IMs parameters, a set of discrete points is extracted from the outputs of dynamic analyses for each record, residing in the DM-IM plane. The single IDA curve is obtained by interpolating these points using the spline interpolation. Investigations of the IDA curves indicate that their shapes have diverse varieties, and none of them is quite similar to each other. Thus, in the following, a few single IDA curves along with the corresponding arranged crack patterns and DamageDisplacement Time History (DDTH) curves are investigated simultaneously to get a better understanding of the seismic behavior of concrete gravity dams.

Figures 5 to 8 show the single IDA curves of Coalinga (record \#8), Mammoth (record \#16), Morgan (record \#20), and Kocaeli (record \#11) earthquakes, respectively. All curves are depicted for DM of AMCD and two IMs of PGA and $S_{a}\left(5 \%, T_{1}\right)$. In addition, three red dashed lines are shown in each figure, specifying some thresholds as Base Level crack initiation (BLci), upper part crack initiation (NZci),

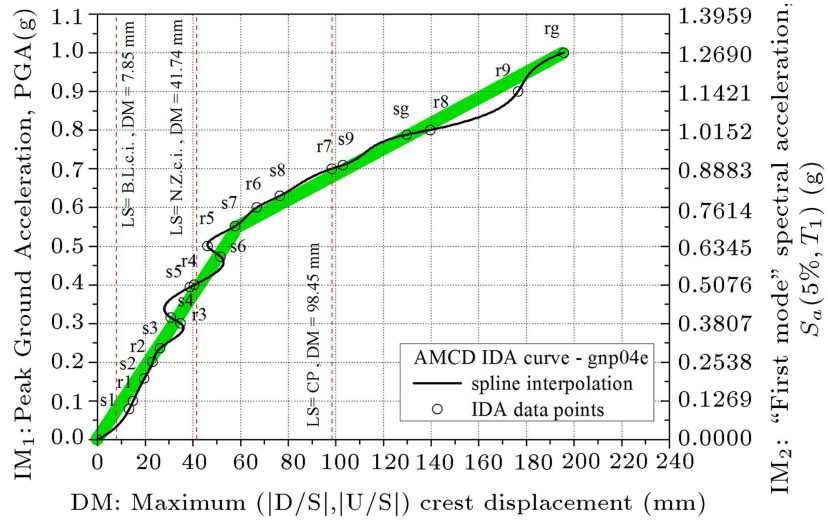

Figure 5. The record \#8 IDA curve.

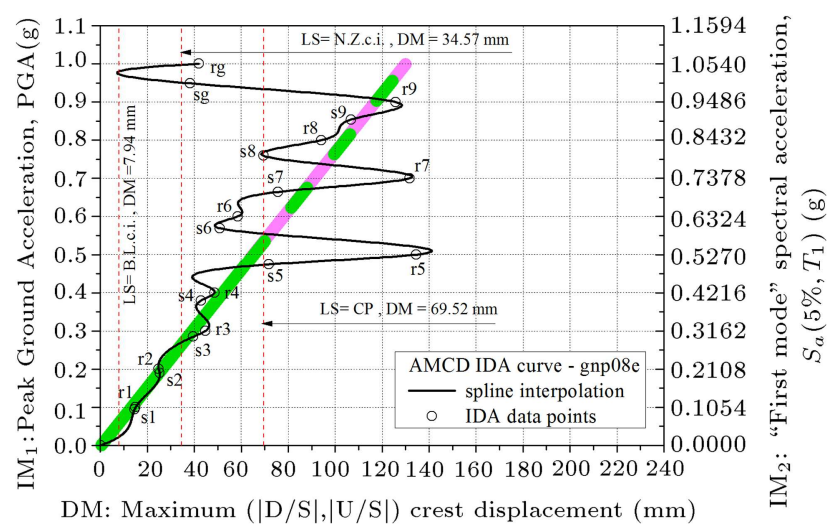

Figure 6. The record \#16 IDA curve.

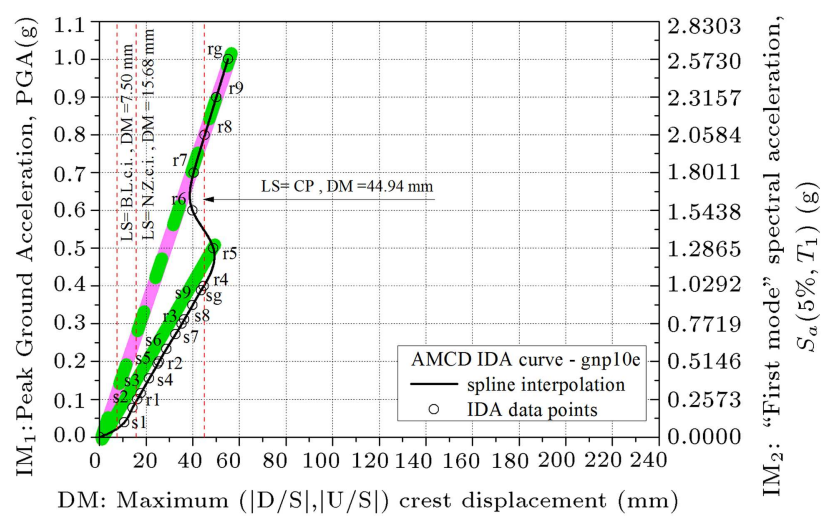

Figure 7. The record \#20 IDA curve.

and Collapse Prevention (CP) LSs. These thresholds are the median value of the structural responses collection at various scale levels of the corresponding record.

The depicted IDA curve in Figure 5 is relatively simple and generally shows the ductile behavior of dam with some slight hardening cases. Figure 6 shows the single IDA curve with a twisting pattern. This curve describes a low ductile structure against excitation of record \#16. The twisting pattern of this IDA curve is formed by successive cycles of softening and hardening segments, which may be due to the changing of damage pattern of the structure. Figure 7 demon- 


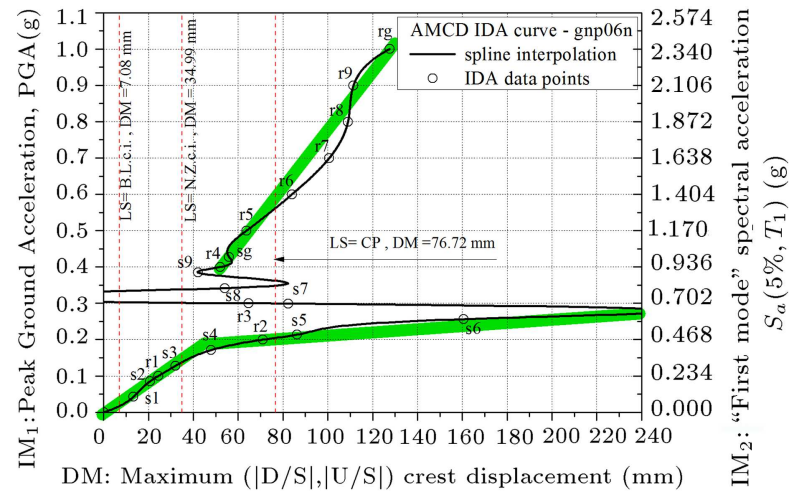

Figure 8. The record \#11 IDA curve.

strates the simple IDA curve with severe hardening, which represents a stiff structural behavior. Usually, hardening phenomenon is observed in IDA curve due to the change of damage pattern, when the structural response decreases at the higher level of IM [16].

A recent study performed by Hariri-Ardebili and Saouma involved the single-IDA curve anatomy investigation [25]. The major differences between this research and their study are in the input seismic load and dam-reservoir interaction modeling. HaririArdebili and Saouma used both horizontal and vertical components of 21 nonpulse-like motions for nonlinear dynamic analysis; however, we used 26 horizontal pulse-like records. In addition, they approximated the dam-reservoir effects using the added mass approach; however, here, the dam-reservoir interaction is included in the time domain analysis using the staggered solution method. They reported four forms of softening response, slight hardening, severe hardening, and wavy response of IDA curves for Pine Flat concrete gravity dam [25]. The forms of IDA curves shown in the present study are compatible to their results, even by a different assumption in simulation.

Demonstrated IDA curve in Figure 8 has a form more complicated than the previous ones do. Here, the sharply softening of curve occurs, which is similar to the definition of the flat line in IDA methodology, yet it is different from flat line. The flat line is defined as to be resulting from infinite DM responses due to numerical instability when any increase in IM is experienced, while, in this study, there is no numerical instability and infinite responses because of employing the ending analyses criteria. On the other hand, a severe hardening is seen in Figure 8 after the sharply softening; this sequence is likened to the phenomenon of structural resurrection.

As a supplementary explanation, crack profiles of record \#11 are shown in Figure 9. As is illustrated in this figure, the cracked configuration of monolith up to s3 scale level consists of only base level crack path (linear section in IDA curve). Sharply softening behavior of dam nearly starts after s3 scale level. The crack profile corresponding to the next IM level of s3 (s4) includes three crack paths: one at the base level and two others at the upper part of the dam (penetrated from U/S and D/S faces into the opposite side). Noticeably, the largest DM response corresponds to s6 scale level, which may be related to the full crack path at the middle level of the dam body (Figure 9). In addition, at the next scale level (s7), the formation of full crack path at the base level possibly leads to the decrease of crest displacement response of structure and occurrence of severe hardening phenomenon. This severe decreasing of large DM response in two sequential IM levels is introduced as a structural resurrection phenomenon in the last paragraph.

Nevertheless, a linear region is seen in the beginning of all single-IDA curves with different extents and slopes. Existence of some slight changes in the local slope in this section expresses the well-known equal displacement rule, where the curve continues in oscillation format around the elastic slope in the inelastic section. This first linear section consists of two lines: the first one from starting point up to BLci and the second one from BLci up to NZci. By the analogy made between the slopes of the mentioned lines, it is found that the intact dam behaves softer than the damaged one when the stable base level cracking is developed. In addition, it is observed that the NZci usually results in softening the behavior of dam that is followed in IDA curve by hardening segment at the higher IM level. The variation of the mentioned cycle

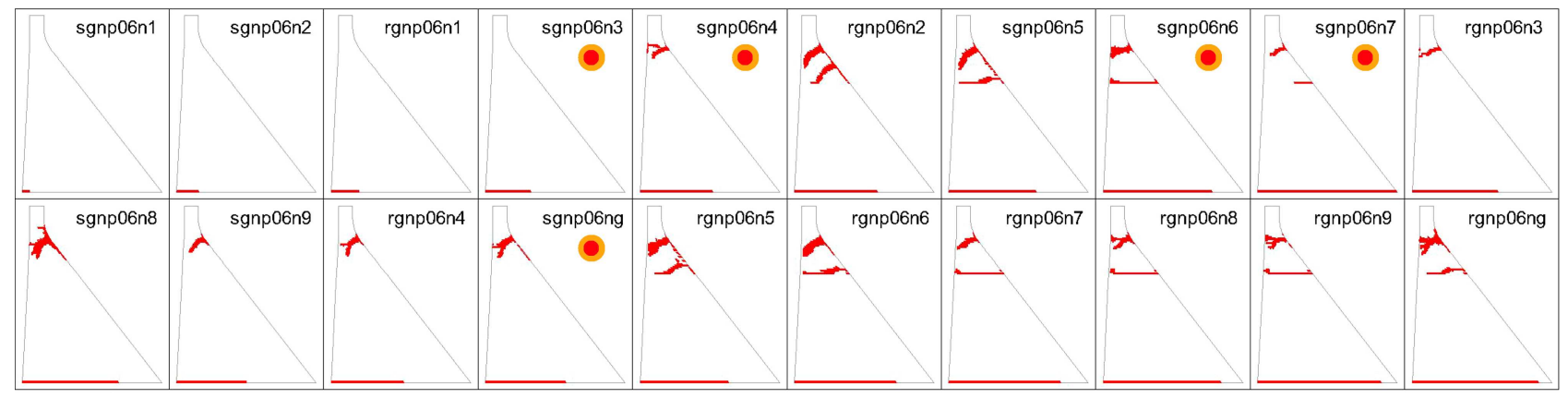

Figure 9. Crack profiles of record \#11 in an increasing manner. 
of Softening/Hardening $(\mathrm{S} / \mathrm{H})$ is quite dependent on earthquake features and is not possible to give any definite statement about it in advance. Such a slight form of cycle is observed in record \#8. In addition, a completely unstable state occurs in record \#11 due to the severe $\mathrm{S} / \mathrm{H}$ cycle. Although the $\mathrm{S} / \mathrm{H}$ cycle happened in the severe form in record \#16, it did not lead to an unstable situation. Usually, after this cycle, the IDA curve continues in a linear trend (such as records \#8, \#11, and \#20) or oscillates around the imaginary line (such as record \#16) in the inelastic section. The number of $\mathrm{S} / \mathrm{H}$ cycles in this section is related to damage pattern changing in the dam body.

The cracked configurations of the monolith at the end time of the analysis for record \#8 are shown in Figure 10. As shown in Figure 10, the predicted crack profiles of analysis corresponding to high IM levels are all reasonably similar to each other; however, the expansion of crack at the dam body is decreased as IM level continues to increase. It appears that the change of the damage pattern of the structure occurred up to a significant intensity level. In other words, there is no change made to the structural damage pattern at IM levels higher than a significant intensity level, and only the damaging speed increases.

Figure 11 shows the marked AMCD single IDA curve of record \#16. Three single IDA curves related to the selective DMs of MCD U/S, MCD D/S, and AMCD of record \#16 are shown in Figure 12. Obviously, from the beginning of excitation of the dam up to the IM of $\mathrm{PGA}=0.364 \mathrm{~g}$, displacement response of the structure is quite affected by the $\mathrm{D} / \mathrm{S}$ direction motion of dam, followed by the influence of $\mathrm{U} / \mathrm{S}$ direction motion, up to the highest IM level. Crack profiles of record \#16 are shown in Figure 13. Figure 14 illustrates four DDTH curves related to the six-scale level of record \#16. DDTH curve includes the time history of both cracking at the dam body and the dam crest displacement. Each vertical gray line in DDTH curve signifies the cracking of one or more structural elements at the same time, and lines over the horizontal axis indicate cracking elements at the base level, whereas lines below this axis indicate the cracking at the upper part of dam.

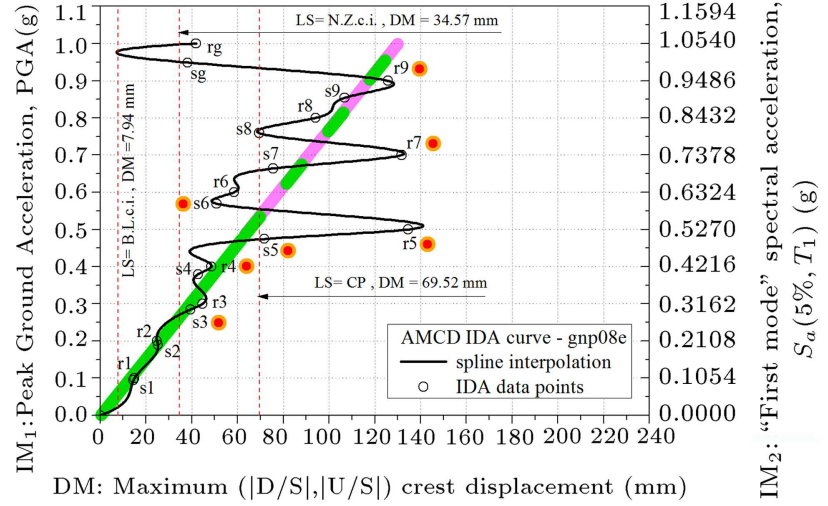

Figure 11. Marked AMCD single IDA curve of record \#16.

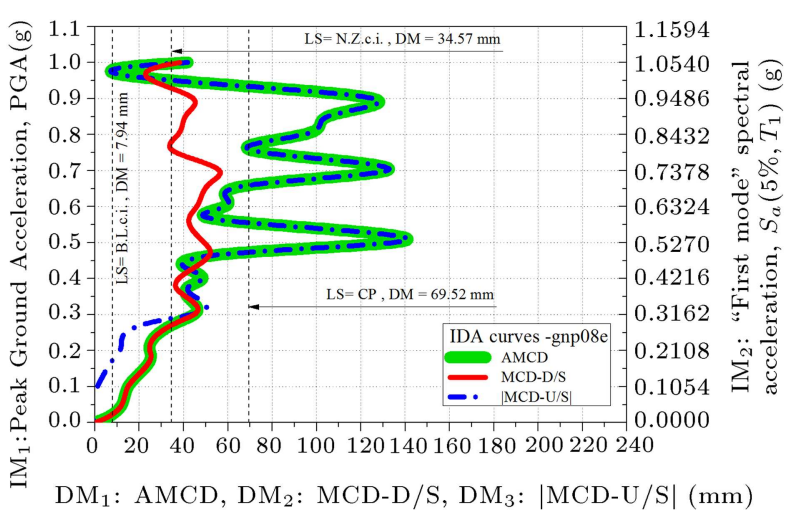

Figure 12. Three single IDA curves of record \#16.

According to the scale-up the intensity level, two different phenomena may occur as earlier yielding and earlier ending. Earlier yielding in stronger shaking happens, because the amplitudes of the primary displacement cycles are growing. Therefore, the importance of the primary cycles boosts, which leads to earlier cracking of structure and its yielding. In addition, the more the amplitudes of the primary displacement cycles rise, the faster the damaging development causing earlier ending of analyses will be. Hence, by increasing the intensity level, the duration time of the analysis usually decreases, namely earlier ending. Both these two phenomena may change the damage pattern of

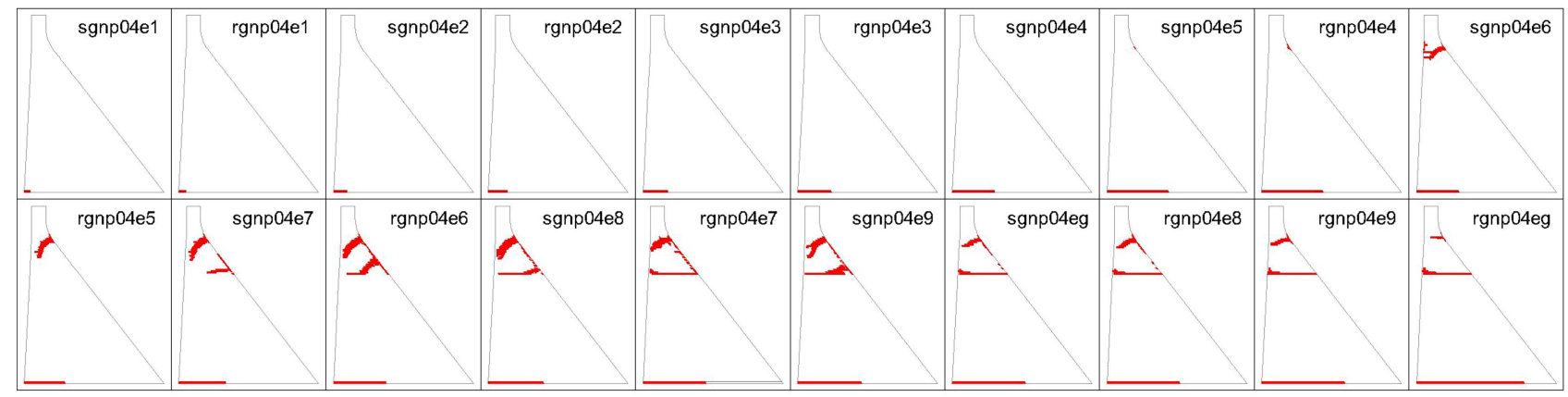

Figure 10. Crack profiles of record \#8 in an increasing manner. 


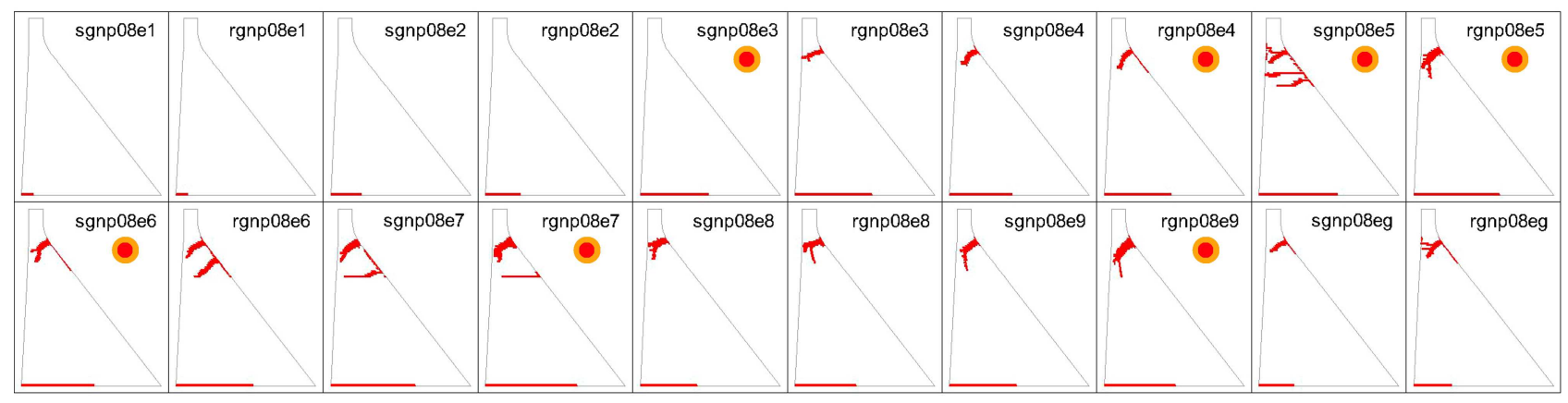

Figure 13. Crack profiles of record \#16 in an increasing manner.
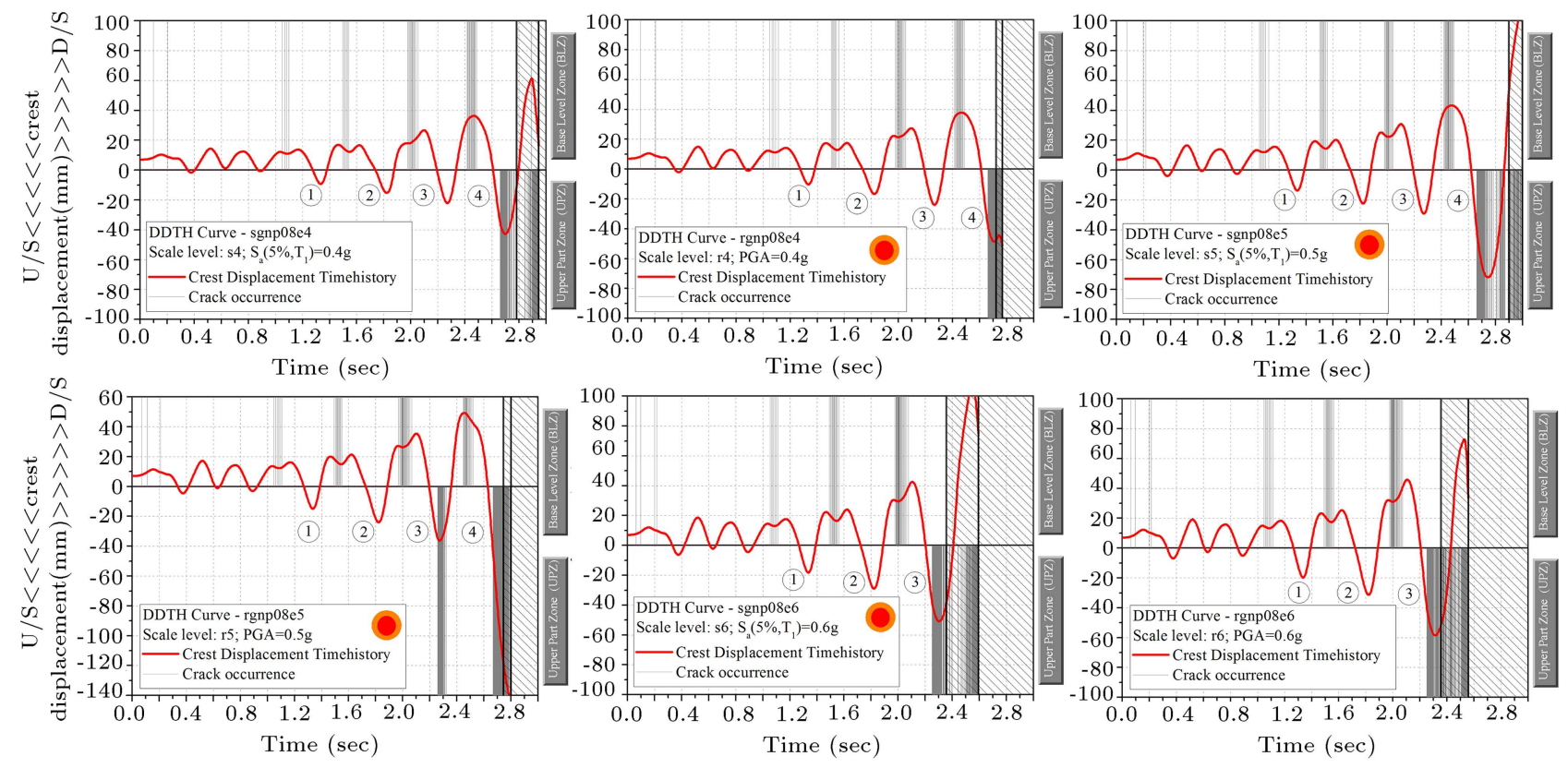

Figure 14. DDTH curves of record \#16.

the structure, and their occurrence can be seen in simultaneous investigation of Figures 11, 13, and 14 .

In the mentioned set of figures, every previous IM level of damage pattern variation was marked by orange-red filled circle. The increase of amplitude in crest displacement time history at the IM level of s5 (Figure 14) brings about damage to pattern variation (Figure 13) with respect to scale of $\mathrm{r} 4$. With the careful study of Figure 14, the occurrence of earlier yielding phenomenon is seen in DDTH curve of $\mathrm{r} 5$ as NZci happens at the third cycle into U/S; however, NZci for s5 IM level occurs at the forth U/S cycle. Moreover, an earlier ending phenomenon is seen in DDTH curve of $\mathrm{s} 6$ scale level with respect to $\mathrm{r} 5$, and it is possible due to the growth of amplitude in crest displacement time history.

\subsection{Summarizing the IDA curves}

There are several methods to summarize the single IDA curves as calculation of the mean, median, and
$16 \%$ and $84 \%$ fractiles of DM values at each IM level. Mean curve is a simple and highly available choice to represent suitable single IDA curves, especially when there are not infinite DMs [12]. However, the median curve is preferable, when it is generally more robust and has more advantages over the other representations [16]. The single-record IDA curves collection and their representative curves for the chosen DMs of U/S MCD, D/S MCD, AMCD, and DFE are separately plotted in Figure 15(a) to (d). All curves are depicted based on the PGA as IM.

As it can be seen from mean and median U/S MCD IDA curves in Figure 15(a), in a constant IM, the value of mean DM is higher than median value of DM. The same trend is observed in Figure 15(b) to (d). In other words, the mean curve is softer than median one. It may be due to the sensitivity of mean value to extreme values/outliers, especially when the sample size is small, and it is well known that the interpolation of data points sometimes causes the generation of very 


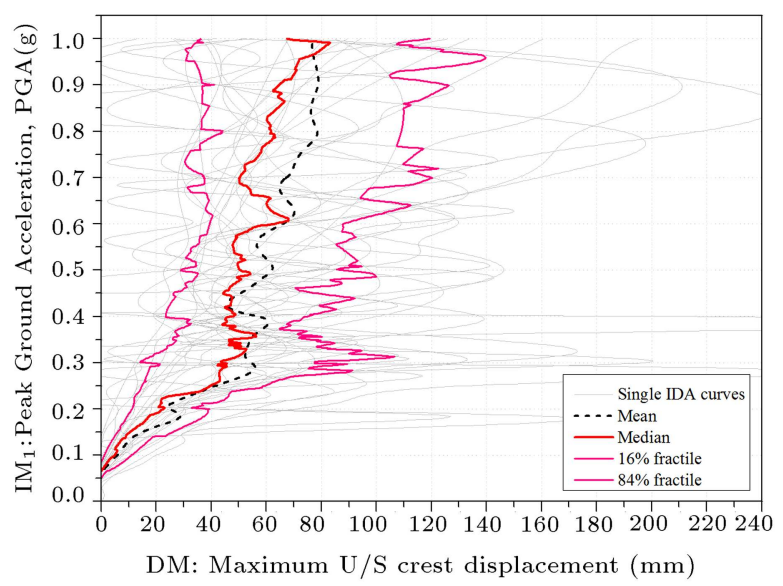

(a)

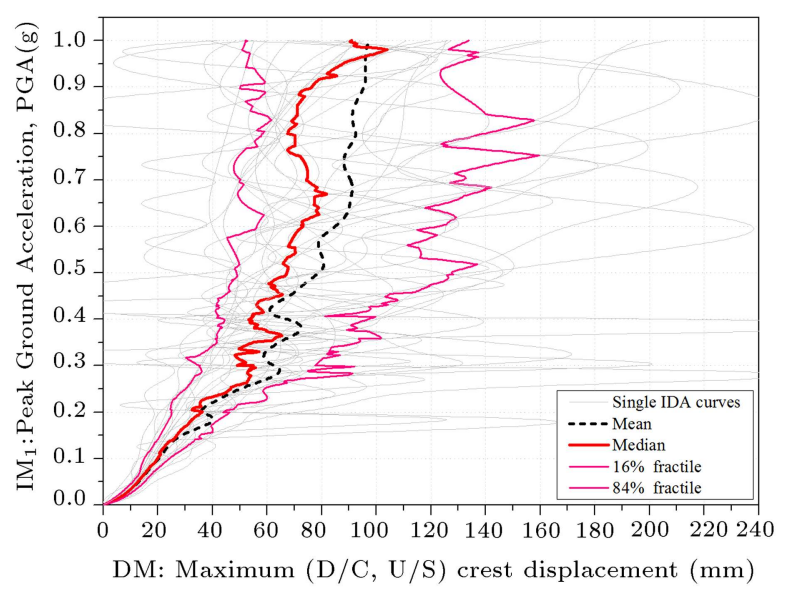

(c)

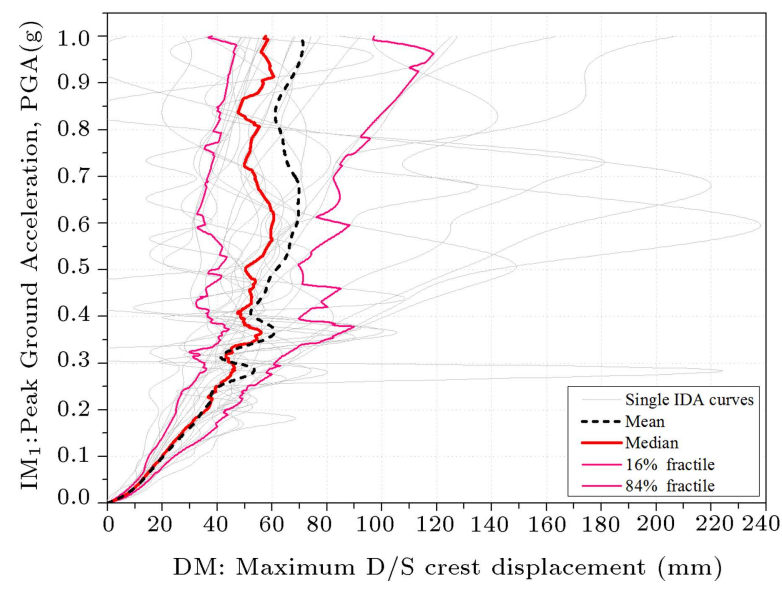

(b)

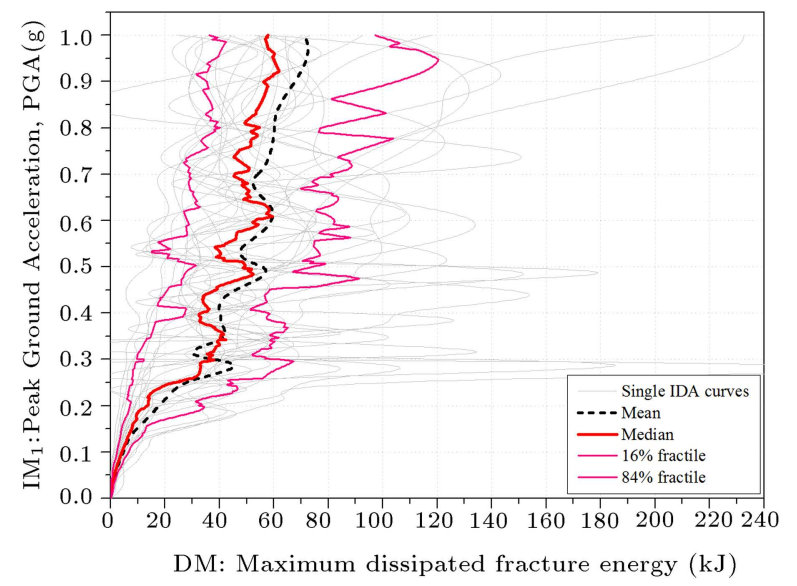

(d)

Figure 15. IDA curves: (a) U/S MCD IDA curve, (b) D/S MCD IDA curve, (c) AMCD IDA curve, and (d) DFE IDA curve.

high and low values. Therefore, explanation of the multi-record IDA has been done using the median curve.

The first elastic linear region in AMCD IDA curve is longer than the two $\mathrm{D} / \mathrm{S}$ and $\mathrm{U} / \mathrm{S}$ ones in crest displacement field; however, it obeys softer behavior. Interestingly, the expression of the well-known equal displacement rule is observed in Figure 15(c) and (d). It appears that the DFE IDA curve is harder than the other IDA curves. In addition, a comparison of Figure 15(c) and (d) indicates that the numbers of $\mathrm{S} / \mathrm{H}$ cycles of two figures are equal. Moreover, it can be visualized that every four-median IDA curve has waving behavior around the imaginary straight line in the inelastic section. Finally, Figure 16 shows three median IDA curves related to the selective DMs of $\mathrm{MCD} U / \mathrm{S}, \mathrm{MCD} \mathrm{D} / \mathrm{S}$, and AMCD.

As is demonstrated in Figure 16, both of MCD $\mathrm{U} / \mathrm{S}$ and MCD D/S curves have significant influence on AMCD IDA curve. Further, it can be said that none of the MCD U/S and MCD D/S curves can singly represent the behavior of dam, sufficiently. Therefore,

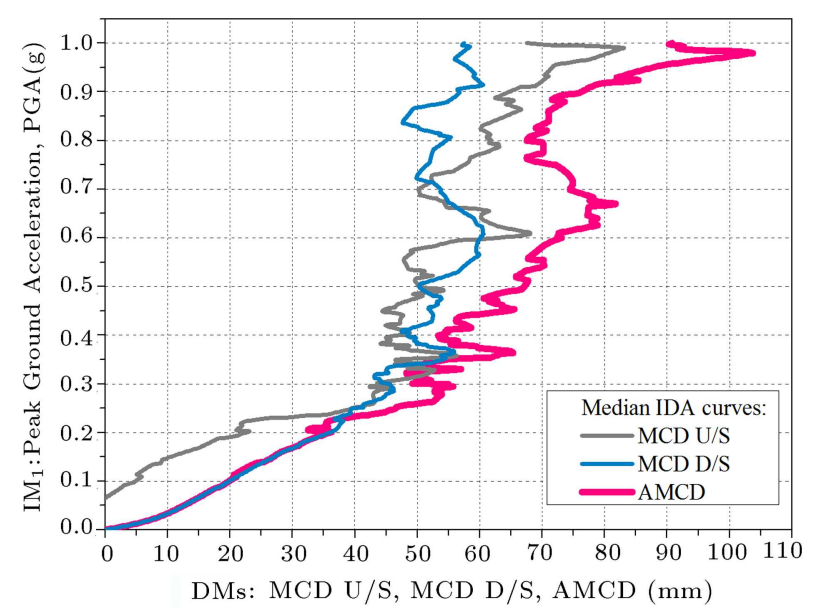

Figure 16. Three median IDA curves related to the selective DMs of MCD U/S, MCD D/S, and AMCD.

the study of seismic behavior of concrete gravity dam is preferable to be done through AMCD curve, since it has better capability to present the behavior of the dam. Usually, at low levels of IM and relatively up to NZci, 
displacement response of the structure is quite affected by the dam's motion towards $\mathrm{D} / \mathrm{S}$ direction in which the two IDA curves of MCD D/S and AMCD overlap each other. In addition, crest displacement response is fairly affected by the U/S direction motion of dam after NZci and at the higher levels of IM.

\subsection{Seismic limit-states of concrete gravity dams}

The main gap between this study and the previous research is described in this section. As mentioned before, the LSs of the system can be predicted using IDA curve; however, in order to have more trustable LSs, it is required that we implement a statistical method. Generated IDA curves of this research at the utmost level of structural behavior correspond to CP LS with regard to ending analyses criteria. In this section, yielding, Collapse Prevention (CP), Base Level crack initiation (BLci), and upper part crack initiation (NZci) LSs would be determined through the study of IDA results and 520 nonlinear transient analyses' outputs. In Table 4, more detailed pieces of information are found regarding the depicted median IDA curves in Figure 15. Structural yielding is one of the typical behaviors of any structure that appears as the transformation of a linear response into nonlinear one. The various responses of the dam are investigated in order to determine the yielding LS threshold with two different approaches. In the first approach, the crest displacement of the dam is evaluated to achieve the yielding threshold. The yielding displacements of the dam into $\mathrm{U} / \mathrm{S}$ and $\mathrm{D} / \mathrm{S}$ are $20.15 \mathrm{~mm}$ and 33.59 $\mathrm{mm}$, respectively, as shown in IDA curves in Figure $15(\mathrm{a})$, and (b) and Table 4 . These certain values $\left(C_{\mathrm{DM}}\right)$ are defined in DM-based fashion, which are dependent on the motion direction.

In the second approach, the motion direction is not considered in the determination of yielding LS. The trend of the crest displacement obeys linear behavior up to $36.27 \mathrm{~mm}$, corresponding to $\mathrm{PGA}=0.201 \mathrm{~g}$, as illustrated in AMCD IDA curve. However, the linear behavior of DFE IDA curve is limited up to PGA = $0.149 \mathrm{~g}$. Therefore, via IM-based method, the yielding LS would be the displacement of $26.83 \mathrm{~mm}$ at IM of
PGA $=0.149 \mathrm{~g}$ in AMCD IDA curve using less IM. Thus, yielding LS threshold would be equal to the crest displacement of $26.83 \mathrm{~mm}$, which was determined based on the evaluation of dam behavior, independent of motion direction (AMCD DM).

Total collapse happens when the response of structure exceeds a certain value. This threshold is named as Collapse Prevention (CP) LS. As illustrated in Table 4, the nonlinear crest displacement ranges vary from $20.15 \mathrm{~mm}$ to $83.14 \mathrm{~mm}$ and from $33.59 \mathrm{~mm}$ to $60.56 \mathrm{~mm}$ with the average rates of $54.00 \mathrm{~mm}$ and $52.03 \mathrm{~mm}$ into U/S and D/S directions, respectively. Although the average values are close to each other and it is possible to choose the smaller one as CP LS threshold, a certain value of DM will be related to some IMs with respect to the twisting form of IDA curve in a nonlinear region. Therefore, there is a need to use IMbased method to determine CP LS. Based on 26 single IDA studies, CP LS occurred at the range of PGA between $0.163 \mathrm{~g}$ and $0.700 \mathrm{~g}$ in different records with the median of $0.267 \mathrm{~g}$. The corresponding value of PGA $=0.267 \mathrm{~g}$ in AMCD IDA curve is 52.80. Interestingly, this value has a small difference compared to CP LS displacement obtained from U/S and D/S MCD IDA curves in DM-based method.

The additional statistical studies have been performed, since the determination of $\mathrm{CP}$ threshold diverse requires special attention. It should be mentioned that, up to now, we have investigated median representation of IDA curve. In this section, all analyses including occurrence of CP LS will be noticed, i.e., only the final analysis based on the ending analyses' criteria is considered. Figure 17 depicts the occurrence of $\mathrm{CP}$ LS based on the horizontal crest displacement of dam versus the PGA of the corresponding record.

Based on Figure 17(a) and (b), the median values of $\mathrm{CP}$ displacement into U/S and $\mathrm{D} / \mathrm{S}$ are $56.27 \mathrm{~mm}$ and $67.68 \mathrm{~mm}$, respectively. Both of these values are greater than CP LS displacement of $52.80 \mathrm{~mm}$. In addition, there is no occurrence of CP LS with IM less than PGA $=0.163 \mathrm{~g}$. Besides, the $84 \%$ fractal of CP LS IM occurrence is $0.300 \mathrm{~g}$ which is higher than $0.267 \mathrm{~g}$, corresponding to the IM level of the defined CP LS. To sum up, selecting the IM of PGA $=0.267 \mathrm{~g}$ with

Table 4. Obtained information of linear and nonlinear limit states using IDA curves (Figure 12).

\begin{tabular}{|c|c|c|c|c|c|c|c|c|}
\hline \multirow[b]{2}{*}{$\begin{array}{l}\text { Figure } \\
\text { ID. }\end{array}$} & \multirow[b]{2}{*}{ DM } & \multicolumn{2}{|c|}{$\begin{array}{c}\text { Infinite slope section } \\
\text { (in all records) }\end{array}$} & \multicolumn{2}{|c|}{$\begin{array}{l}\text { Linear region } \\
\text { (median curve) }\end{array}$} & \multicolumn{3}{|c|}{$\begin{array}{l}\text { Nonlinear region } \\
\text { (median curve) }\end{array}$} \\
\hline & & Existing & IM range & Start point & End point & DM range & $\begin{array}{l}\text { Average of } \\
\text { DM range }\end{array}$ & $\begin{array}{c}\text { DM value in } \\
\text { IM }_{C P} \text { of } 0.267 \mathrm{~g} \\
\left(\mathrm{IM} \mathrm{M}_{C P} \text { range }\right. \\
=(0.163 \mathrm{~g}-0.700 \mathrm{~g})\end{array}$ \\
\hline (a) & $\mathrm{U} / \mathrm{S} \mathrm{MCD}(\mathrm{mm})$ & $\sqrt{ }$ & $0.00-0.141 \mathrm{~g}$ & $(0.00,0.066 \mathrm{~g})$ & $(-20.15,0.191 \mathrm{~g})$ & $-(20.15-83.14)$ & -54.00 & -43.17 \\
\hline (b) & $\mathrm{D} / \mathrm{S} \mathrm{MCD}(\mathrm{mm})$ & $\times$ & - & $(0.00,0.00)$ & $(33.59,0.188 \mathrm{~g})$ & $33.59-60.56$ & 52.03 & 43.60 \\
\hline (c) & $\mathrm{AMCD}(\mathrm{mm})$ & $\times$ & - & $(0.00,0.00)$ & $(36.27,0.201 \mathrm{~g})$ & $32.39-103.83$ & 67.30 & 52.80 \\
\hline (d) & DFE $(\mathrm{kJ})$ & $\sqrt{ }$ & $0.00-0.058 \mathrm{~g}$ & $(0.00,0.00)$ & $(7.706,0.149 \mathrm{~g})$ & $7.706-61.911$ & 43.31 & 32.33 \\
\hline
\end{tabular}




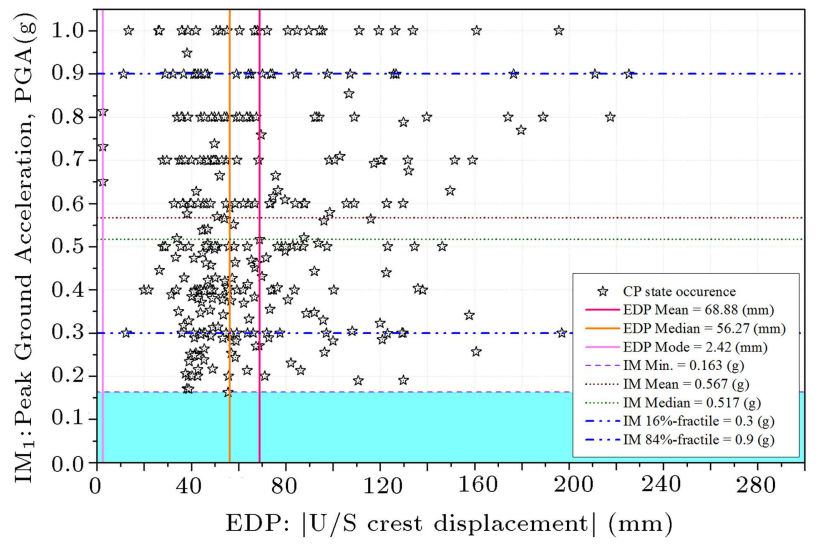

(a)

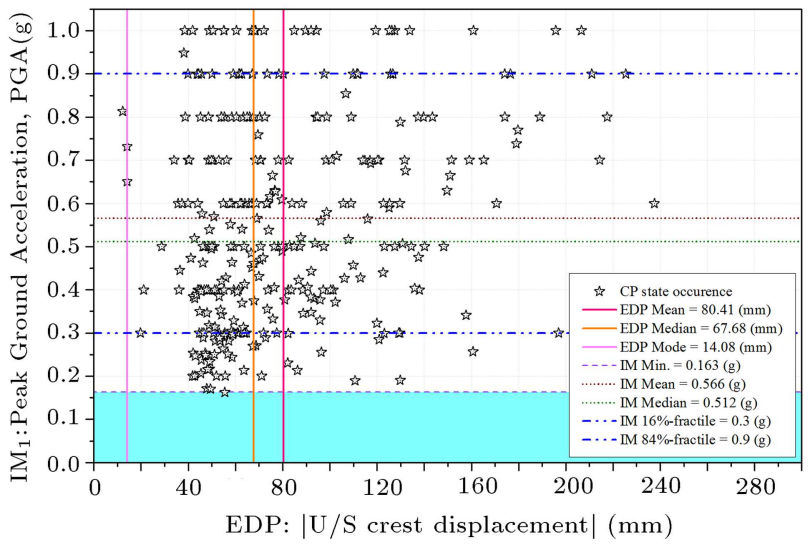

(b)

Figure 17. The occurrence of CP limit state at various IM levels: (a) U/S MCD and (b) D/S MCD.

the corresponding DM of crest displacement $=52.80$ $\mathrm{mm}$ as $\mathrm{IM}_{\mathrm{CP}}$ and $\mathrm{DM}_{\mathrm{CP}}$, respectively, would be rather conservative determination.

On the other hand, BLci and NZci are probable LSs in concrete gravity dams. Generally, the base region of dam is cracked at the first $D / S$ vibration cycles of the structure. In addition, fracture of the base level is possible under the medium intensity of earthquake loading. In this study, it is observed that the cracking at the base level always commences from heel, and BLci occurs usually before NZci. Nevertheless, in few cases, the first crack at the dam body appears at the D/S face of the upper part. In addition, a crack has never occurred on the U/S face of the upper part of the dam before BLci. Generally, D/S and U/S face cracking is formed under the influence of dam motion into U/S and $\mathrm{D} / \mathrm{S}$ directions, respectively, as it was observed in the studied DDTH curves.

In order to determine BLci and NZci LSs, a statistical analysis has been done using the dynamic analysis results. It is noticed that the sequence of cracking at the dam body (the first base region, and then upper part cracking, or vice versa) has not been considered. Therefore, both directions of dam motion may lead to NZci. To address the mentioned purpose, maximum crest displacement up to BLci and NZci was separately extracted from the 520 analysis outputs. We classified these data sets into three categories: MCD $\mathrm{D} / \mathrm{S}, \mathrm{MCD} \mathrm{U} / \mathrm{S}$, and AMCD. Crack initiation at the base region of the dam is demonstrated in Figure 18 as star points, showing the crest displacement versus the
PGA of record. Figure 18(a) to (c) correspond to MCD D/S, MCD U/S, and AMCD, respectively. Figures 18 and 19 are depicted in the same frame; however, each star point in Figure 19 shows the crack initiation at the upper part of the dam (NZci).

It is seen in Figure 18 that, for IM level less than $\mathrm{PGA}=0.027 \mathrm{~g}$, there is no occurrence of BLci under the D/S motion as well as PGA of $0.085 \mathrm{~g}$ for $\mathrm{U} / \mathrm{S}$ direction. The median values of categories of MCD D/S, MCD U/S, and AMCD are $8.04 \mathrm{~mm}$, $7.72 \mathrm{~mm}$, and $8.18 \mathrm{~mm}$, respectively. Thus, the crest displacement corresponding to BLci is selected equal to $7.72 \mathrm{~mm}$ conservatively.

Figure 18(b) shows that, in some cases, dam moves into $\mathrm{U} / \mathrm{S}$ direction at the start of excitation. This condition may lead to the occurrence of D/S NZci before BLci at high-intensity levels, i.e., in fact, the relatively large crest displacement into $\mathrm{U} / \mathrm{S}$ direction firstly causes D/S NZci; then, the next oscillation of dam into D/S leads to BLci. This condition can be identified as scattered star points in Figure 18(b) and (c).

There is no occurrence of NZci at the IM levels less than PGA $=0.163 \mathrm{~g}$, as it is shown in Figure 19. The median values of categories of MCD D/S, MCD U/S, and AMCD are $44.75 \mathrm{~mm}, 35.90 \mathrm{~mm}$, and $46.45 \mathrm{~mm}$, respectively. Therefore, the crest displacement of 35.90 $\mathrm{mm}$ is selected as NZci threshold, conservatively. As a summary based on the crest displacement of dam, the determined thresholds of BLci, yielding, NZci, and CP LSs are tabulated in Table 5.

Table 5. Defined limit-states based on the crest displacement value.

\begin{tabular}{ccccc}
\hline Limit-state & BLci & Yielding & NZci & CP \\
\hline Horizontal crest displacement (mm) & 7.72 & 26.83 & 35.90 & 52.80 \\
Drift ratio (relative deflection) (\%)* & 0.006 & 0.022 & 0.029 & 0.043 \\
\hline
\end{tabular}

*Drift ratio or relative deflection: the top of the dam deflection relative to the heel. 


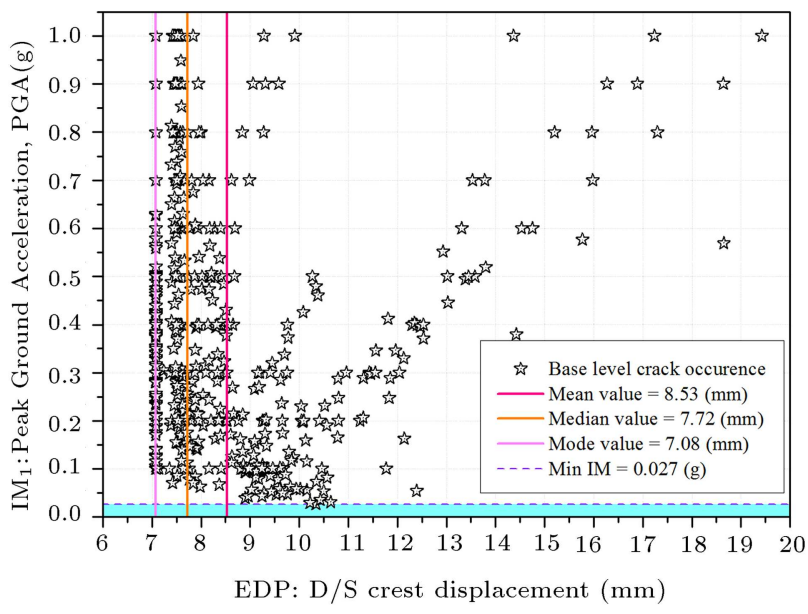

(a)

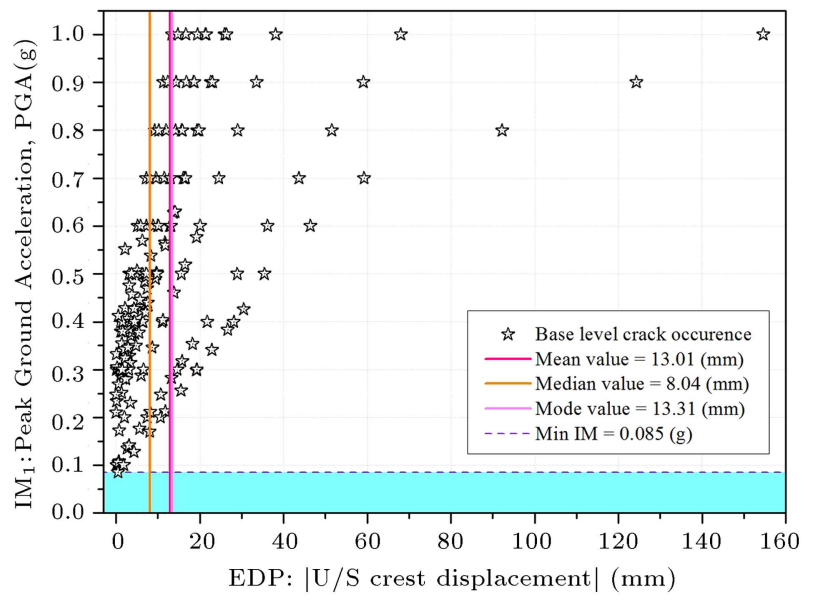

(b)

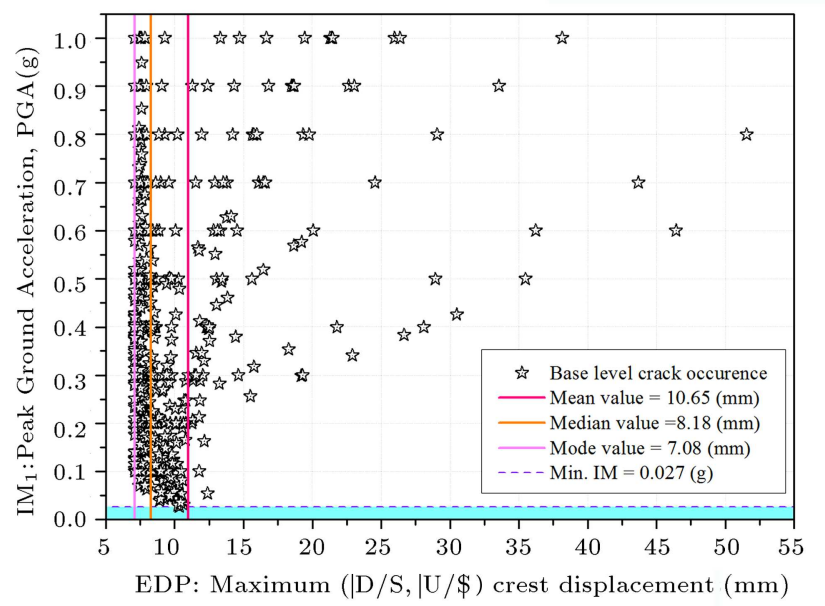

(c)

Figure 18. The occurrence of BLci at various IM levels: (a) D/S MCD, (b) U/S MCD, and (c) AMCD.

Table 6. Information of the concerned studies: displacement or drift ratio LSs.

\begin{tabular}{|c|c|c|c|c|c|c|c|c|}
\hline \multirow{2}{*}{ Z } & \multirow{2}{*}{ 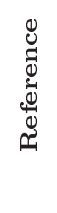 } & \multirow{2}{*}{ 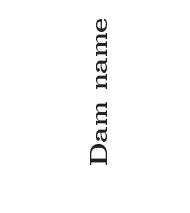 } & \multirow{2}{*}{ 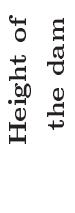 } & \multirow{2}{*}{ 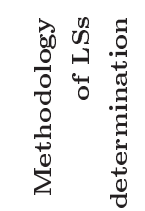 } & \multirow{2}{*}{ 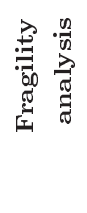 } & \multicolumn{2}{|c|}{ Thresholds of LSs } & \multirow{2}{*}{ 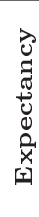 } \\
\hline & & & & & & $\begin{array}{r}\text { displacement } \\
(\mathrm{mm})\end{array}$ & Drift ratio (\%) & \\
\hline 1 & {$[12]$} & Pine Flat & 122 & $\mathrm{IDA} \sqrt{ } \mathrm{SPO}$ & $x$ & $14.29,33.78,41.38,62.05$ & $0.012,0.028,0.034,0.051$ & $\sqrt{ }$ \\
\hline 2 & {$[14]$} & Pine Flat & 122 & $x$ & $\sqrt{ }$ & $10,25,35$ & $0.008,0.021,0.029$ & $\sqrt{ }$ \\
\hline 3 & [22] & Oued el Fodda & 101 & $x$ & $\sqrt{ }$ & $5,20,40$ & $0.005,0.02,0.04$ & $\sqrt{ }$ \\
\hline 4 & [25] & Pine Flat & 122 & IDA & $\sqrt{ }$ & Using capacity curve & - & $\sqrt{ }$ \\
\hline 5 & [28] & Pine Flat & 122 & IDA & $\sqrt{ }$ & $220,560,1000,1750$ & $0.18,0.459,0.82,1.434$ & $x$ \\
\hline 6 & {$[37]$} & Bluestone & 53 & $\times$ & $\sqrt{ }$ & 8,15 & $0.014,0.028$ & $\sqrt{ }$ \\
\hline 7 & {$[40]$} & Koyna & 103 & $\times$ & $\times$ & 103 & 0.1 & $\sqrt{ }$ \\
\hline
\end{tabular}

\subsection{Comparison with the related studies}

In some of the previous studies related to the evaluation of seismic performance of concrete gravity dams, LSs of the structure have been defined by horizontal crest displacement or drift ratio. In many of these studies, the thresholds of LSs have been assumed according to the experiences of the practitioners, and it is not achieved by computation, especially in fragility context. Table 6 presents the LSs thresholds of the concerned studies.

As shown in Table 6 , the drift ratio change is in the range of $0.005 \%$ to $0.1 \%$, except for one case [28]. As it is observed, the reported figures by Ansari and 


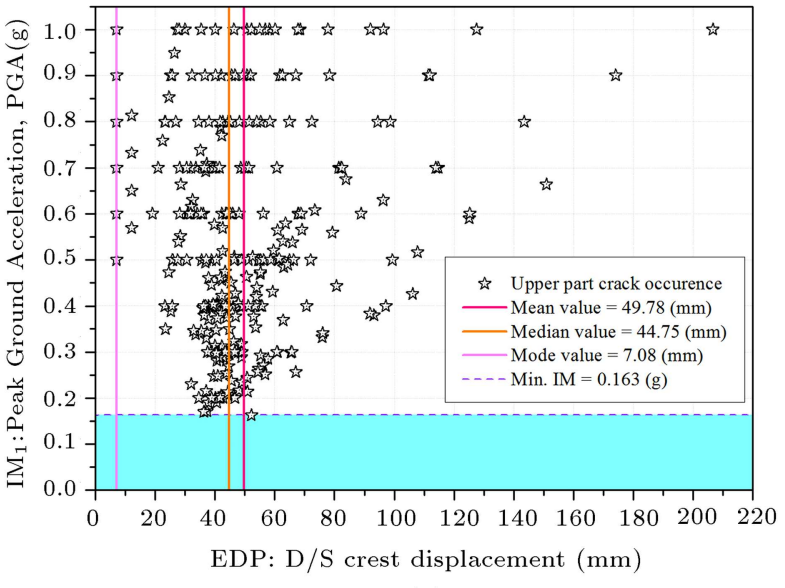

(a)

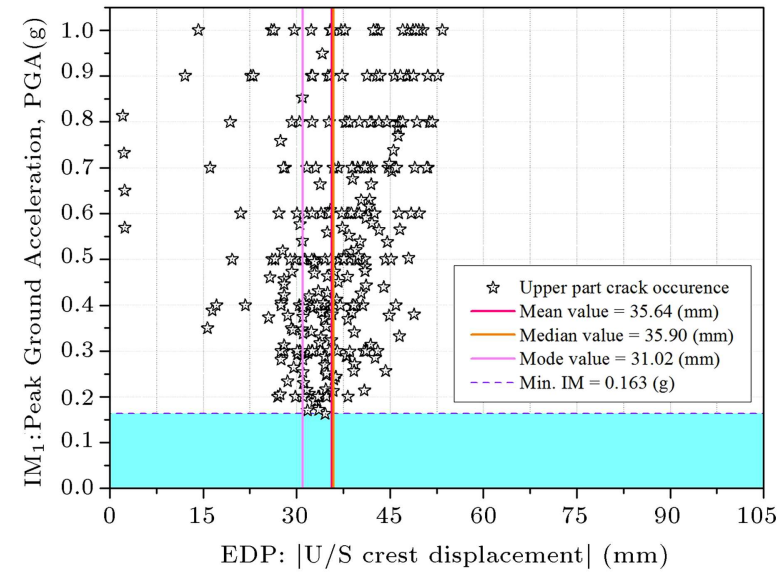

(b)

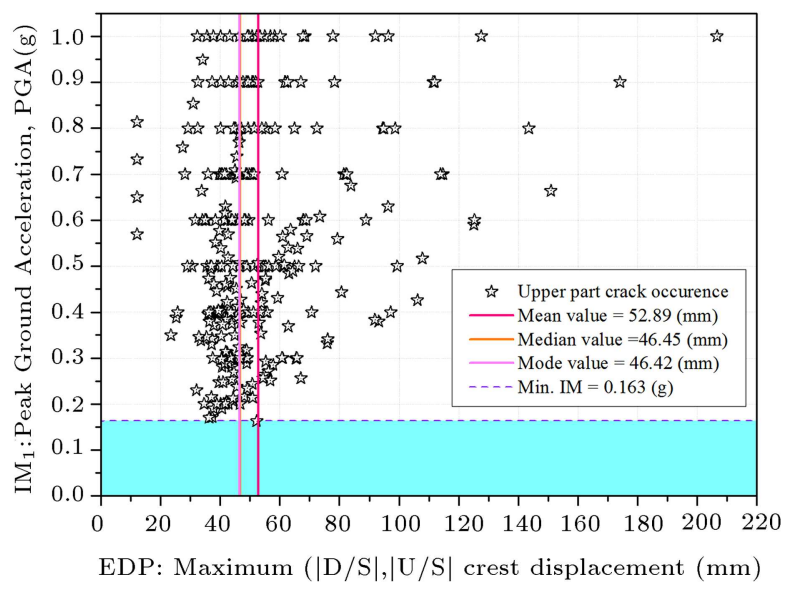

(c)

Figure 19. The occurrence of NZci at various IM levels: (a) D/S MCD, (b) U/S MCD, and (c) AMCD.

Agarwal [28] are much larger than the expected values and do not satisfy the relevant literature reviews. However, the findings of the current study are consistent with those of the other ones.

Alembagheri and Ghaemian [12] determined the yield and ultimate LSs in Pine Flat gravity dam using combination of the IDA and static pushover (SPO) results. Their methodology was fruitful, but manipulation of two different nonlinear analyses was effortful, and using the combination of their results to specify LSs was complicated. They did not use the obtained LSs for fragility analysis. Ansari and Agarwal [28] developed a fragility function based on crest displacement. They found the mean values of crest displacement values of $0.22 \mathrm{~m}, 0.56 \mathrm{~m}, 1.0 \mathrm{~m}$, and $1.75 \mathrm{~m}$ as slight, moderate, extensive, and severe damage states, using IDA. Obviously, the stated values are in an extra ordinary range and cannot be assumed in real practice, since such large values of displacement bring about dam instability, leading to eventual loss of pool control. However, these excessive amounts of displacement for LSs have been avoided in our study due to using the ending analyses criteria. By benefiting from IDA results, Hariri-Ardebili and Saouma [25] generated the collapse fragility curves for Pine Flat dam. They fitted a probability distribution function on the tagged failure points and determined the corresponding cumulative distribution function. After the determination of fragility parameters (dispersion and median), they have plotted the fragility curves. In their valuable study, they left the middle LSs and no data figures were obtained for threshold of collapse LS. In the present research, statistical analysis along with IDA enabled determination of middle performance levels (such as BLci, yielding, and NZci) with acceptable accuracy, as well as CP. Therefore, the methodology for determining these LSs confirms the superiority of this study, compared to the related studies.

\section{Fragility and probability of exceeding}

One can classify methods to derive vulnerability functions into three general approaches: empirical, analytical, and expert opinion. Analytical methods use 
engineering first principles to estimate the vulnerability function. Almost all analytical methods employ the same four analytical stages as hazard analysis, structural analysis, damage analysis, and loss analysis. At the third stage of the method (damage analysis), the structural responses (computed at the second stage) are input to component fragility functions to estimate probabilistic damage to each damageable component at each level of excitation [41]. In addition, fragility analyses are used to assess the performance of structures [42].

In the fragility concept, it is essential to have some determined structural LSs for the probabilitybased analyses. Therefore, in this research, fragility of LSs has been calculated using the defined LSs of BLci, yielding, NZci and CP LSs (Table 5), named as limit states numbers 1 to 4 , respectively. The exceeding probabilities of the LSs based on the selective EDP versus various IM levels of PGA are determined by

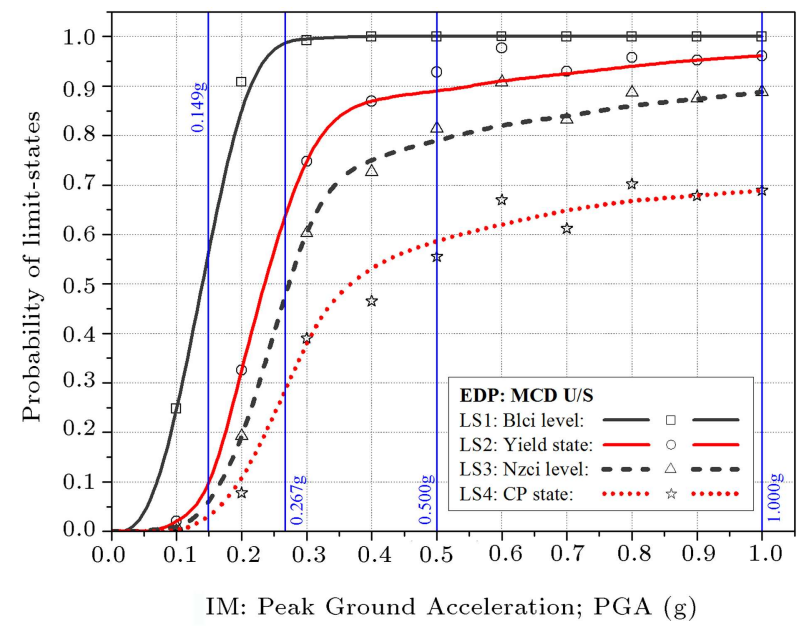

(a)

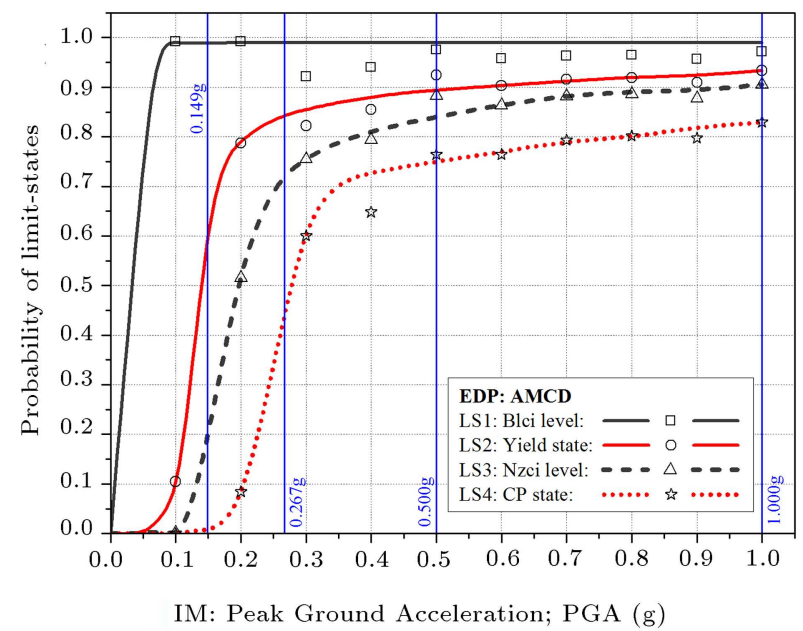

(c) fragility function, as in Eq. (2):

$$
\begin{aligned}
P[L S] & =P[E D P>L S \mid P G A] \\
& =1-P[E D P<L S \mid P G A] .
\end{aligned}
$$

This probability could be presented by lognormal distribution as in Eq. (2):

$$
P[L S]=1-\Phi\left[\frac{\operatorname{In}(L S)-\mu}{\sigma}\right]
$$

where $\Phi$ is the standard normal probability integral, $\mu$ is the mean of data, and $\sigma$ is logarithmic standard deviation. The fragility curves of LS1 to LS4 for different EDPs of MCD U/S, MCD D/S, and AMCD are shown in Figure 20(a) to (c), respectively. Figure 20(d) shows all fragility curves corresponding to every EDP at a single plane.

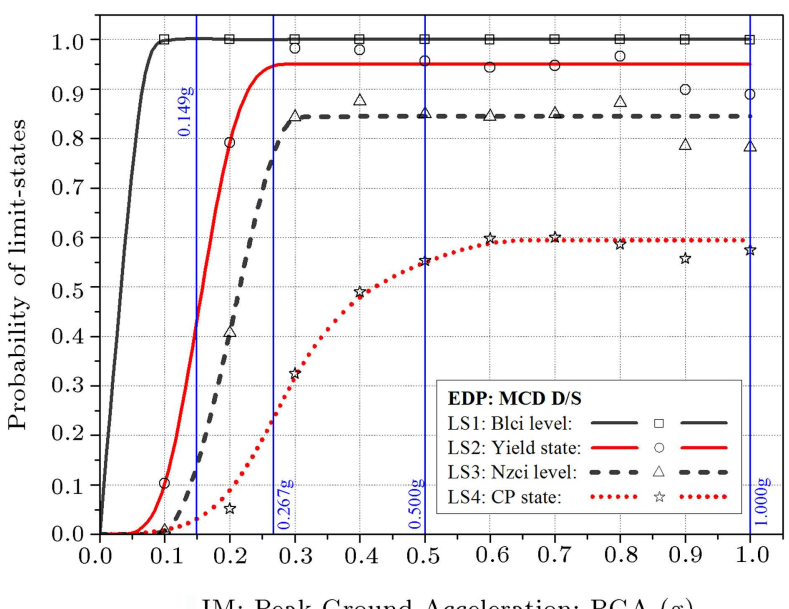

(b)

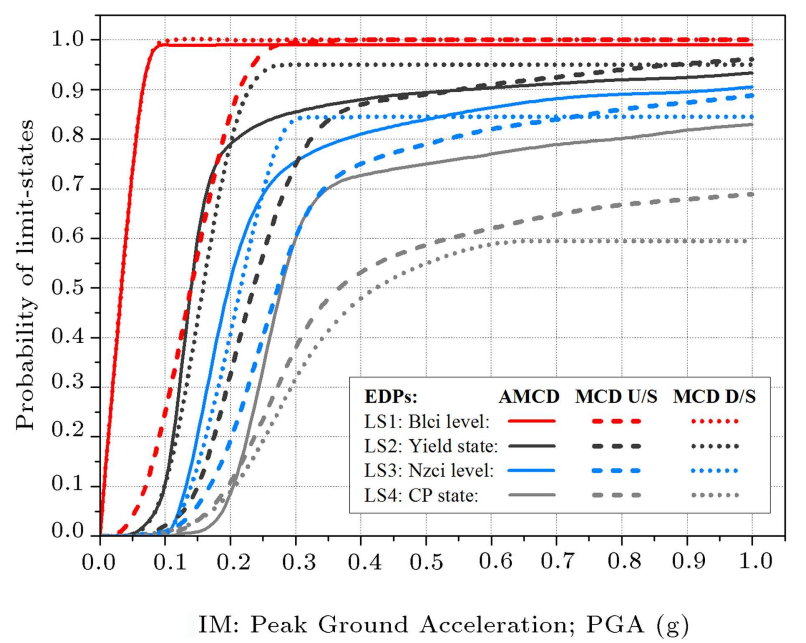

(d)

Figure 20. The exceeding probability of the performance levels based on some EDPs: (a) EDP: MCD U/S, (b) EDP: MCD D/S, (c) EDP: AMCD, and (d) EDPs: MCD U/S, MCD D/S and AMCD. 
These curves have been smoothed using the smoothing spline. The location of some data points around the smooth curve may be due to the variation of the damage pattern of the structure. The data points corresponding to the IM of PGA $=0.6 \mathrm{~g}$ have the longest distance from the related fragility curves, as shown in Figure 20(a). Similarly, the longest distance of data points for Figure 20(b) and (c) is related to IM levels of $\mathrm{PGA}=0.9 \mathrm{~g}$ and $\mathrm{PGA}=0.4 \mathrm{~g}$, respectively. Dispersion of data points around the LS4 fragility curve is higher than the other curves for EDP of MCD U/S. In addition, the most scattering data points around the fragility curves correspond to LS2 and LS1 for EDPs of MCD D/S and AMCD, respectively.

For the simplicity of the conclusion on the subject of fragility, the probabilities of exceeding each defined LS at four PGAs of $0.149 \mathrm{~g}, 0.267 \mathrm{~g}, 0.500 \mathrm{~g}$, and $1.00 \mathrm{~g}$ are shown in Figure 21 for three selective EDPs. The PGA values of $0.149 \mathrm{~g}$ and $0.267 \mathrm{~g}$ respectively correspond to yielding and CP LSs, determined in the previous section using IDA technique. Moreover, PGA values of $0.500 \mathrm{~g}$ and $1.00 \mathrm{~g}$ have been chosen as the middle and extreme intensity levels in this study. In addition, the value of each probability is illustrated in Figure 21, in which, for the simplest comparison of different EDPs, the maximum probability of each LS at the specified PGA is signed by red color and is named here by Maximum Probability of Exceeding (MPE).

As is seen, there are 16 comparison cases as far as MPE is concerned in Figure 21. The numbers of MPE are 9, 4, and 6 cases for EDPs of MCD D/S, $\mathrm{MCD} U / \mathrm{S}$, and AMCD, respectively; the first of the two EDPs are equal in 3 cases. On the other hand, probabilities of LS1 to LS3 based upon the MCD U/S are lower than those based on the other ones at the IM of $\mathrm{PGA}=0.149 \mathrm{~g}$. Besides, it is observed that cracking at the base region has great probability. Nevertheless, the AMCD-based probability of LS1 (BLci) never gets to one in contrast with EDPs of $\mathrm{D} / \mathrm{S}$ and U/S MCD. A comparison of different EDPs at various IM levels is possible in Figure 22 based on each LS.

Figure 22(a) shows the fragility curves for BLci LS. The curves of EDPs of AMCD and MCD D/S are relatively in compliance with each other in Figure 22(a); however, MCD D/S curve is located above AMCD one with a slight gap. On the other hand, MCD $\mathrm{U} / \mathrm{S}$ curve is different from the two others up to PGA $=2.72 \mathrm{~g}$ and it leads to low-predicted BLci probability, as seen in Figure 22(a). After PGA $=2.72 \mathrm{~g}$, the MCD U/S curve has good agreement with other ones.

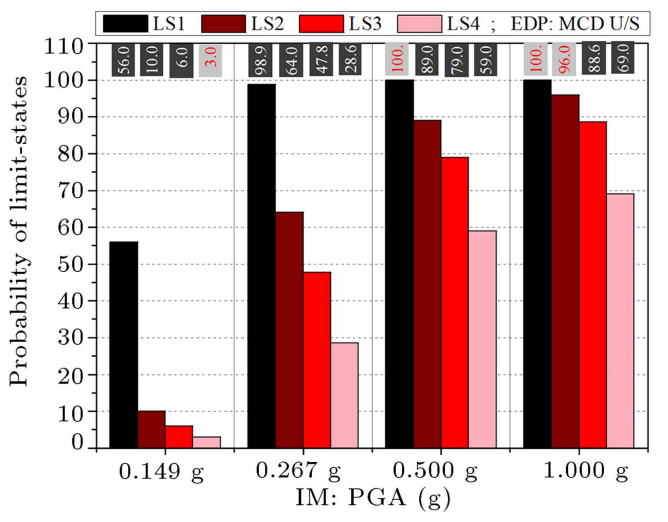

(a)

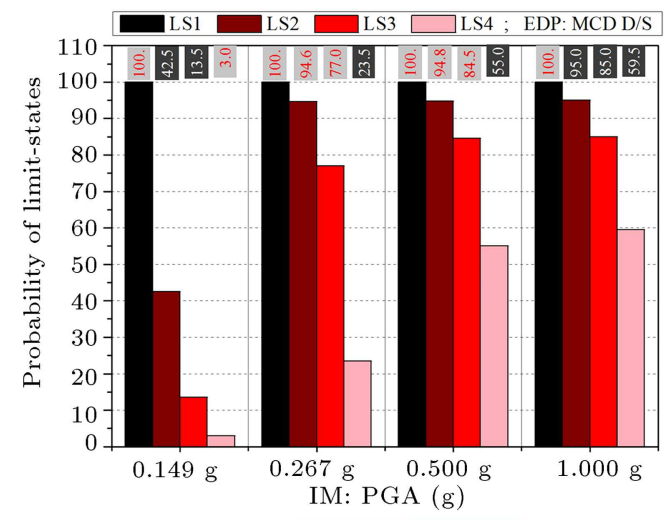

(b)

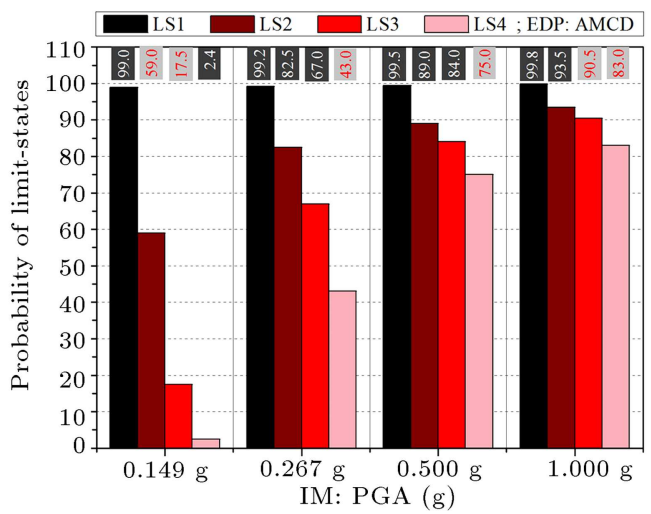

(c)

Figure 21. The values of each probability: (a) EDP: MCD U/S, (b) EDP: MCD D/S, and (c) EDP: AMCD. 


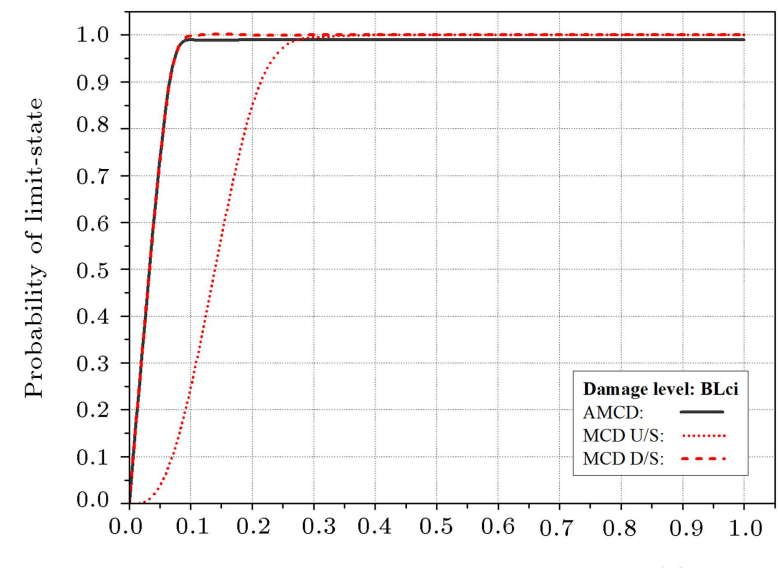

IM: Peak Ground Acceleration; PGA (g)

(a)

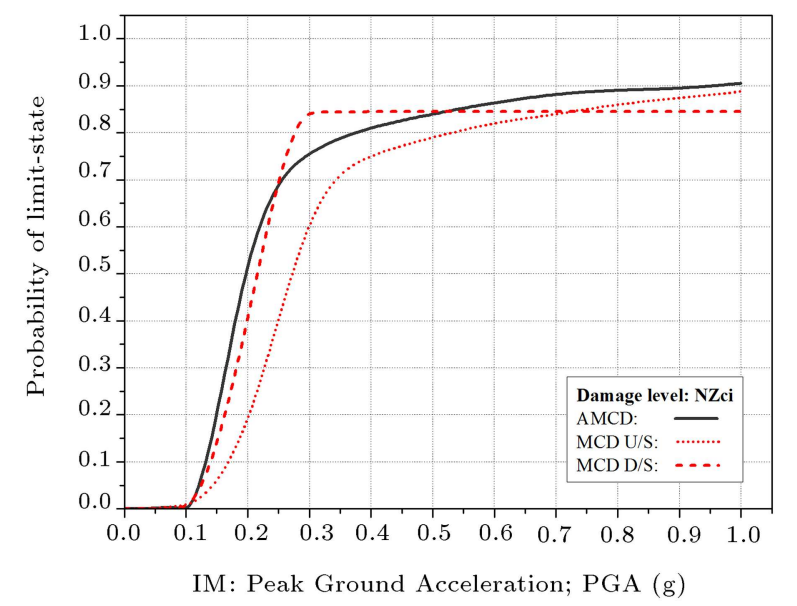

(c)

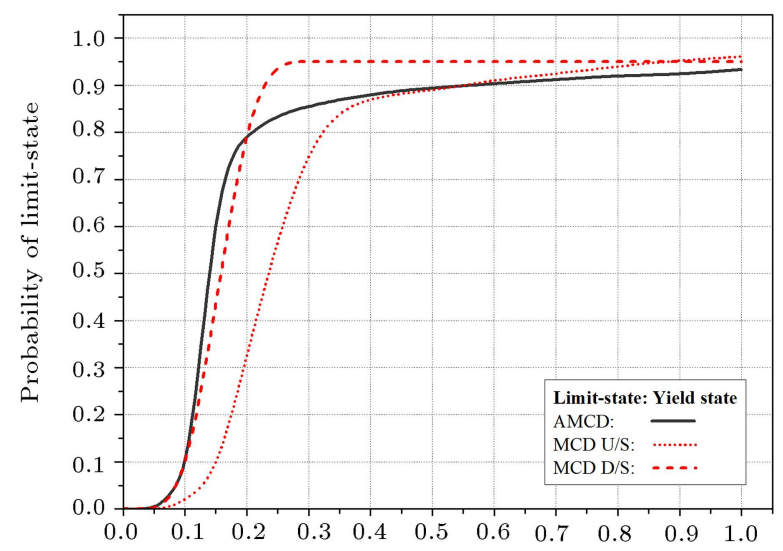

IM: Peak Ground Acceleration; PGA (g)

(b)

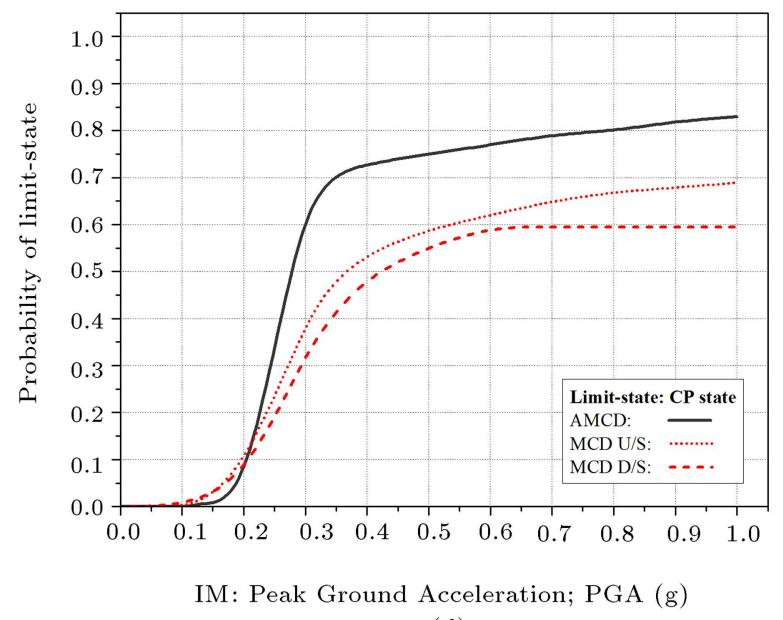

(d)

Figure 22. Fragility curves for LSs: (a) LS1: Limit-state of BLci, (b) LS2: Limit-state of yielding, (c) LS3: Limit-state of NZci, and (d) LS4: Limit-state of CP.

The mentioned difference may be due to the direct effect of $\mathrm{D} / \mathrm{S}$ motion on cracking at the base level. Therefore, it seems that the prediction of probability of BLci based on the MCD D/S is conservative and preferable.

The good agreement of AMCD and MCD D/S fragility curves up to PGA $=0.200 \mathrm{~g}$ is seen in Figure 22(b). After the IM of $0.200 \mathrm{~g}$, the AMCD curve gets close to $\mathrm{MCD} \mathrm{U} / \mathrm{S}$ one, up to $\mathrm{PGA}=0.350 \mathrm{~g}$, and then lies on it relatively, while MCD D/S after the PGA of $0.200 \mathrm{~g}$ sharply goes up and reaches 0.95 at $\mathrm{PGA}=0.290 \mathrm{~g}$ from the probability of 0.79 . The MCD D/S continues with minor slope from IM of 0.290 $\mathrm{g}$ up to the highest level of IM. It is better to pay attention to the IM of PGA $=0.870 \mathrm{~g}$, since prior to this point, MCD D/S curve is located above the two other curves; after that, MCD U/S goes up. Of course, all curves relatively comply with each other after the PGA of $0.550 \mathrm{~g}$. Besides, all three curves represent the zero probability of yielding LS, nearly up to $0.040 \mathrm{~g}$. It is found from Figure 22(b) that the prediction of probability of yielding state (LS2) based on the MCD $\mathrm{D} / \mathrm{S}$ is conservative and preferable, as well as BLci LS.

The fragility curves of NZci LS are demonstrated in Figure 22(c). On the basis of these curves, the probability of LS3 is zero, up to PGA $=0.100 \mathrm{~g}$. From PGA $=0.100 \mathrm{~g}$ to $0.500 \mathrm{~g}$, the ratio of the probability change to the change of the IM is high in all curves. This rate decreases after the IM of $0.500 \mathrm{~g}$ and all curves gradually agree with each other. Prior to $\mathrm{PGA}=0.500 \mathrm{~g}, \mathrm{MCD} \mathrm{D} / \mathrm{S}$ curve is located above the two other curves; after that, AMCD goes up. However, after PGA of $0.500 \mathrm{~g}$, the difference in $y$-axis of the two curves of MCD D/S and AMCD is less than $7 \%$, as seen in Figure 22(c), i.e., it is said that MCD D/S EDP is an important parameter in probabilistic seismic performance evaluation of gravity dams. Interestingly, this point is found in the previous section where IDA study shows that displacement response of the structure is quite affected by the motion of dam towards D/S direction up to NZci.

The fragility curves of CP LS are illustrated in 
Figure 22(d). It is observed that two curves of MCD $\mathrm{D} / \mathrm{S}$ and $\mathrm{U} / \mathrm{S}$ are aligned with each other and are placed above the AMCD fragility curve, up to PGA $=0.180 \mathrm{~g}$. However, after the IM of $0.180 \mathrm{~g}$, the two curves are gradually separated and MCD U/S curve is located above MCD D/S one, while the $\mathrm{y}-$ axis difference of the two curves is less than $10 \%$. In addition, AMCD has been placed above the other two curves, after PGA of $0.180 \mathrm{~g}$. It clearly shows that the seismic performance assessment of dams in the CP LS, only based on the EDPs of MCD D/S and MCD U/S, is not conservative and needs special attention to the AMCD EDP. The reason for such necessity is the large deformation of dam into both directions of $\mathrm{D} / \mathrm{S}$ and $\mathrm{U} / \mathrm{S}$, leading to the excessive amount of damage in $\mathrm{CP}$ LS. On the other hand, both of D/S and U/S motions have influence on value of AMCD at the high intensity levels, especially after NZci. Thus, AMCD is more suitable EDP for defining the nonlinear performance of the dam, where the dominant response of the structure is nonlinear in the CP LS.

\section{Conclusion}

The probabilistic seismic performance of concrete gravity dams was investigated using fragility analysis. To address the determination of structural responses, the Incremental Dynamic Analysis method (IDA) was applied to the tallest monolith of the dam-reservoir finite-element model with rigid foundation.

It was found that the damaged dam behaved stiffer than the intact one, when the stable base level cracking was developed. The upper part crack initiation (NZci) usually resulted in softening the behavior of dam followed in IDA curve by hardening segment at a higher IM level. Usually, after this S/H cycle, the IDA curve continued in linear trend or oscillated around the imaginary line in the inelastic section.

A new comprehensive method in terms of IDA and statistical analysis was used to determine seismic LSs of concrete gravity dams. Thresholds of four Limit States (LSs) as Base Level crack initiation (BLci), yielding, upper part crack initiation (NZci), and Collapse Prevention (CP) were estimated using the IDA results and 520 nonlinear transient analyses' outputs. In this regard, applying an appropriate ending analyses' criteria would increase the credibility of LSs. Since the AMCD and DFE IDA curves represent the global state of structural condition, using either of the IDA curves of D/S and U/S MCD in seismic assessment of dam, without any consideration of AMCD and DFE ones, is not recommended.

Fragility analysis showed that BLci was highly probable LS in Pine Flat dam, while CP LS was relatively unlikely. In addition, it was seen that the prediction of probability of BLci based on the EDP of
MCD D/S was conservative and preferable, similar to that about yielding LS. Besides, exceeding probability of NZci LS was reliably determined by consideration of both D/S MCD and AMCD. It was shown that AMCD was more suitable EDP for probability prediction of CP LS. Generally, it is noteworthy that the MCD D/S EDP is an important parameter in probabilistic seismic performance evaluation of concrete gravity dams, as well as AMCD.

Based on this research, we suggest that the overall structure performance should be limited to $0.05 \%$ based on drift ratio as collapse prevention LS for concrete gravity dams. Regarding the future research opportunities, the LSs determination with respect to the dam-reservoir interactions must be achieved; for the future study, the effect of base and lift joints will be also considered. Furthermore, the developed fragility curves in this study could be improved by considering epistemic uncertainty. In this research, there is no definite relationship between the defined LSs (yielding and CP) and qualitative description of damage (damage state). However, the defined LSs used in the probabilistic seismic vulnerability assessment of a gravity dam can be used in the damage analysis stage of PBEE framework, in which after the plotting of fragility curve for the required EDP, the probability of exceeding each LS can be calculated through the related fragility curve.

\section{List of abbreviation}

$\begin{array}{ll}\text { 2D } & \text { Two-dimensional } \\ \text { AD } & \text { Arch Dam } \\ \text { AMCD } & \text { Absolute value of Maximum Crest } \\ & \text { Displacement } \\ \text { BLci } & \text { Base Level crack initiation } \\ \text { C } & \text { Curve } \\ \text { CDM } & \text { Certain values of Damage Measure } \\ \text { CP } & \text { Collapse Prevention } \\ \text { CLA } & \text { Cloud Analysis } \\ \text { DDTH } & \text { Damage-Displacement Time History } \\ \text { DFE } & \text { Dissipated Fracture Energy } \\ \text { DM } & \text { Damage Measure } \\ \text { DMCP } & \text { Damage Measure of Collapse } \\ \text { DOF } & \text { Prevention state } \\ \text { D/S } & \text { Degrees Of Freedom } \\ \text { EBE } & \text { Down-Stream direction } \\ \text { EDP } & \text { Energy Balance Error } \\ \text { ETA } & \text { Engineering Demand Parameter } \\ \text { FE } & \text { Endurance Time Analysis } \\ \text { GD } & \text { Finite-Element } \\ & \text { Gravity Dam }\end{array}$


IDA Incremental Dynamic Analysis

IM Intensity Measure

IMCP Intensity Measure of Collapse Prevention state

LE Linear

LHS Latin Hypercube Sampling

LS Limit-State

MCD Maximum Crest Displacement

MCS Monte Carlo Simulation

MPE Maximum Probability of Exceeding

Ms $\quad$ Surface magnitudes

MSA Multiple Stripe Analysis

NL Non-Linear

NZci Upper part crack initiation

OW Overflow Weir

PBEE Performance-Based Earthquake Engineering

PEER Pacific Earthquake Engineering

Research

PFM Potential Failure Mode

PGA Peak Ground Acceleration

S Surface

$S_{a}(5 \%, T 1)$ Spectral acceleration at the first mode

$S_{v}(5 \%, T 1)$ Spectral velocity at the first mode

SPO Static pushover

$\mathrm{S} / \mathrm{H} \quad$ Softening/Hardening

U/S Up-Stream direction

\section{References}

1. http://en.wikipedia.org/wiki/Dam (2016).

2. IIEES "Manjil-rudbar earthquake on june 20, 1990", Technical Report No. 70-90-1, International Institute of Earthquake Engineering and Seismology (IIEES), Tehran, Iran (1991).

3. Morrison Knudsen Corporation, Report on the Initial Assessment of the Effects of the January 17, 1994 Northridge/San Fernando Earthquake on Pacoima Dam, Phase I, Technical Report, Department of Public Works: Los Angeles (1994).

4. USCOLD "Observed performance of dams during earthquakes", Technical Report, USCOLD Committee on Earthquake, United States Committee on Large Dams (1992).

5. Chopra, A.K. and Chakrabarti, P. "The Koyna earthquake and the damage to Koyna Dam", Seismol. Soc. Am., Bull., 63, pp. 381-397 (1973).

6. Gunay, S. and Mosalam, K.M. "Peer performancebased earthquake engineering methodology, revisited", J. of Earthq. Eng., 17(6), pp. 829-858 (2013).
7. Porter, K. "An overview of peers performance-based earthquake engineering methodology", 9th Intl. Conf. on Appl. of Stats. and Prob. in Civ. Eng. (ICASP9), San Francisco, CA, pp. 973-980 (2003).

8. FERC-PFMA "FERC guidance document: potential failure mode analysis, draft version", Technical Report, Federal Emergency Regulatory Committee, USA (2005).

9. Hariri-Ardebili, M. and Saouma, V. "Seismic fragility analysis of concrete dams: A state-of-the-art review", J. of Struct. Eng., 128, pp. 374-399 (2016).

10. Hariri-Ardebili, M., "Performance based earthquake engineering for concrete dams", Ph.D. Thesis, University of Colorado (2015).

11. Hariri-Ardebili, M., Saouma, V., and Porter, K. "Quantification of seismic potential failure modes in concrete dams", Earthq. Eng. and Struct. Dynam., 45, pp. 979-997 (2016). DOI: 10.1002/eqe.2697

12. Alembagheri, M. and Ghaemian, M. "Seismic assessment of concrete gravity dams using capacity estimation and damage indexes", Earthq. Eng. and Struct. Dynam., 42, pp. 123-144 (2013).

13. Alembagheri, M. and Ghaemian, M. "Damage assessment of a concrete arch dam through nonlinear incremental dynamic analysis", Soil Dynam. and Earthq. Eng., 44, pp. 127-137 (2013).

14. Hariri-Ardebili, M. and Saouma, V. "Probabilistic seismic demand model and optimal intensity measure for concrete dams", Struct. Saf., 59, pp. 67-85 (2016).

15. Hariri-Ardebili, M. and Saouma, V. "Sensitivity and uncertainty quantification of the cohesive crack model", Eng. Frac. Mech., 155, pp. 18-35 (2016).

16. Vamvatsikos, D. and Cornel, C.A. "Incremental dynamic analysis", Earthq. Eng. and Struct. Dynam., 31, pp. 491-514 (2002).

17. De Araújo, J. and Awruch, A. "Probabilistic finite element analysis of concrete gravity dams", Adv. in Eng. Softw., 29, pp. 97-104 (1998).

18. Tekie, P.B. and Ellingwood, B. "Seismic fragility assessment of concrete gravity dams", Earthq. Eng. and Struct. Dynam., 32, pp. 2221-2240 (2003).

19. Mirzahosseinkashani, S. and Ghaemian, M. "Seismic fragility assessment of concrete gravity dams", 29th Annual USSD Conf., Nashville, Tennessee, US (2009).

20. Lupoi, A. and Callari, C. "The role of probabilistic methods in evaluating the seismic risk of concrete dams", In: Dolšek, M., Editor; Protect. of Built Environ. Against Earthq., Springer, pp. 309-329 (2011).

21. Yücel, A. "Seismic analysis of concrete gravity dams including dam-foundation-reservoir interaction", Master's Thesis, Turkey, Middle East technical University (2013).

22. Abdelhamid, H., Mahmoud, B., and Hussein, M. "Seismic fragility and uncertainty analysis of concrete gravity dams under near-fault ground motions", Civ. and Environ. Res., 5, pp. 123-129 (2013). 
23. Ju, B. and Jung, W. "Evaluation of seismic fragility of weir structures in South Korea", Math. Prob. in Eng., 2015, Article ID 391569 (2015). http://dx.doi.org/10.1155/2015/391569

24. Ghanaat, Y., Patev, R., and Chudgar, A. "Seismic fragility analysis of concrete gravity dams", 15 th World Conf. on Earthq. Eng., Lisbon, Portugal (2012).

25. Hariri-Ardebili, M. and Saouma, V. "Collapse fragility curves for concrete dams: comprehensive study", J. of Struct. Eng., ASCE, 142(10) (2016). http://dx.doi.org/10.1061/(ASCE)ST.1943$541 \mathrm{X} .0001541$

26. Bernier, C., Padgett, J.E., Proulx, J., and Paultre, P. "Seismic fragility of concrete gravity dams with spatial variation of angle of friction, case study", J. of Struct., 142(5), 05015002 (2015).

27. Bernier, C., Monteiro, R., and Paultre, P. "Using the conditional spectrum method for improved fragility assessment of concrete gravity dams in eastern Canada", Earthq. Spectra (2016).

28. Ansari, M.I. and Agarwal, P. "Categorization of damage index of concrete gravity dam for the health monitoring after earthquake", J. of Earthq. Eng., 20, pp. 1222-1238 (2016).

29. Yao, X., Elnashai, A., and Jiang, J. "Analytical seismic fragility analysis of concrete arch dams", 15th World Conf. on Earthq. Eng., Lisbon, Portugal (2012).

30. Zhong, H., Li, H., and Bao, Y. "Seismic risk analysis of an arch dam", Appl. Mech. and Mat., 353-356, pp. 2020-2023 (2013).

31. Kadkhodayan, V., Aghajanzadeh, M., and Mirzabozorg, H. "Seismic assessment of arch dams using fragility curves", Civ. Eng. J., 1(2), pp. 14-20 (2015).

32. BUREC, Mid-Pacific Region, Upper San Joaquin River Basin Storage Investigation, Raise Pine Flat Dam, Department of Water Resources, California (2003).

33. Bhattacharjee, S.S. and Leger, P. "Application of NLFM models to predict cracking in concrete gravity dams", J. of Struct. Eng. ASCE, 120, pp. 1255-1271 (1994).

34. Baker, J.W. "Quantitative classification of near-fault ground motions using wavelet analysis", Seismol. Soc. Am., Bull., 97, pp. 1486-1501 (2007).

35. Ghaemian, M. "Manual of NSAG-DRI, a computer program for nonlinear seismic analysis of gravity dams including dam-reservoir-foundation interaction", (2008).

36. Filiatrault, A., Leger, P., and Tinawi, R. "On the computation of seismic energy in inelastic structures", Eng. Struct., 16, pp. 425-436 (1994).

37. Ghaemian, M. and Ghobarah, A. "Nonlinear seismic response of concrete gravity dams with dam-reservoir interaction", Eng. Struct., 21, pp. 306-315 (1999).
38. Kurama, Y. and Farrow, K. "Ground motion scaling methods for different site conditions and structure characteristics", Earthq. Eng. and Struct. Dynam., 32, pp. 2425-2450 (2003).

39. Soysal, B.F., Binici, B., and Arici, Y. "Investigation of the relationship of seismic intensity measures and the accumulation of damage on concrete gravity dams using incremental dynamic analysis", Earthq. Eng. and Struct. Dynam., 45, pp. 719-737 (2016).

40. Hariri-Ardebili, M. and Saouma, V. "Quantitative failure metric for gravity dams", Earthq. Eng. and Struct. Dynam., 44, pp. 461-480 (2015) DOI: 10.1002/eqe.2481

41. Porter, K., A Beginner's Guide to Fragility, Vulnerability, and Risk, University of Colorado Boulder, USA (2017).

42. Argyroudis, S. and Kaynia, A.M. "Analytical seismic fragility functions for highway and railway embankments and cuts", Earthq. Eng. and Struct. Dynam., 44, pp. 1863-1879 (2015). DOI: $10.1002 /$ eqe. 2563

\section{Biographies}

Mohammad Ali Sotoudeh is a PhD Candidate in the Civil Engineering Department of Science and Research Branch of Islamic Azad University (IAU), Tehran, Iran. His research interests include work on the seismic assessment of concrete gravity dams, dynamic response of gravity and arch dams, the nonlinear behavior of concrete dams and probabilistic seismic analysis of dams.

Mohsen Ghaemian is a Professor at the Civil Engineering Department of Sharif University of Technology, Tehran, Iran. His current research activities include the dynamic responses of gravity and arch dams, dam reservoir interaction effects, seismic response of dams due to non-uniform excitations and the nonlinear behavior of concrete dams.

Abdolreza Sarvghad Moghadam is an Assistant Professor in the International Institute of Earthquake Engineering and Seismology (IIEES), Tehran, Iran. At IIEES, he is also the Director of Structural Engineering Research Center and board member of the Center of Excellence on Risk Management. His main research interests are development of three-dimensional pushover analysis methods for asymmetric structures, analysis and design of high-rise buildings, and seismic vulnerability and retrofitting of existing structures. He is a member of committees in charge of developing and updating different building codes in Iran such as Seismic Design of Buildings, Guidelines for Seismic Retrofitting of Existing Structures, and Guidelines for Rapid Screening of Buildings. 